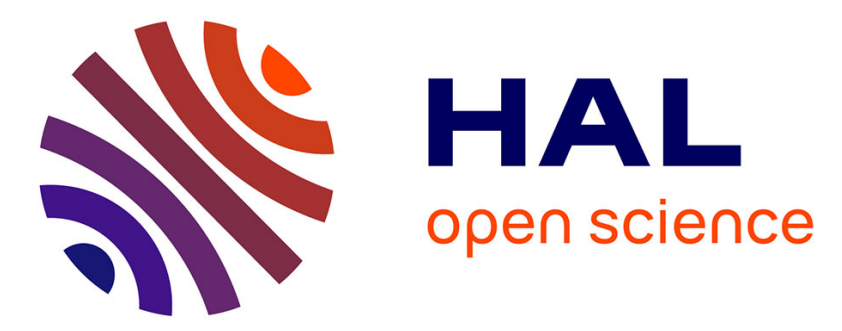

\title{
Stabilization of Fragmental Polystyrene Nanoplastic by Natural Organic Matter: Insight into Mechanisms
}

Alice Pradel, Séléna Ferreres, Cloé Veclin, Hind El Hadri, Maud Gautier, Bruno Grassl, Julien Gigault

\section{- To cite this version:}

Alice Pradel, Séléna Ferreres, Cloé Veclin, Hind El Hadri, Maud Gautier, et al.. Stabilization of Fragmental Polystyrene Nanoplastic by Natural Organic Matter: Insight into Mechanisms. ACS ES\&T Water, 2021, 1 (5), pp.1198-1208. 10.1021/acsestwater.0c00283 . insu-03185053

\section{HAL Id: insu-03185053 https://hal-insu.archives-ouvertes.fr/insu-03185053}

Submitted on 6 Apr 2021

HAL is a multi-disciplinary open access archive for the deposit and dissemination of scientific research documents, whether they are published or not. The documents may come from teaching and research institutions in France or abroad, or from public or private research centers.
L'archive ouverte pluridisciplinaire HAL, est destinée au dépôt et à la diffusion de documents scientifiques de niveau recherche, publiés ou non, émanant des établissements d'enseignement et de recherche français ou étrangers, des laboratoires publics ou privés. 
1 Stabilization of fragmental polystyrene nanoplastic by natural organic matter:

\section{Insight into mechanisms}

3 Alice Pradel $^{\mathrm{a}^{*}}$, Séléna Ferreres ${ }^{\mathrm{a}}$, Cloé Veclin ${ }^{\mathrm{b}}$, Hind El Hadri ${ }^{\mathrm{b}}$, Maud Gautier ${ }^{\mathrm{a}}$, Bruno Grassl ${ }^{\mathrm{b}}$, Julien

4 Gigault ${ }^{\mathrm{a}, \mathrm{c}^{*}}$

$5 \quad{ }^{a}$ Univ Rennes, CNRS, Géosciences Rennes - UMR 6118, 35000 Rennes, France

$6 \quad{ }^{b}$ CNRS/ Univ Pau \& Pays Adour/ E2S UPPA, Institut des sciences analytiques et de physicochimie pour

7 l'environnement et les matériaux, UMR 5254, 64000, Pau, France

$8{ }^{c}$ TAKUVIK laboratory, CNRS/Université Laval, 1045, av. de la Médecine, Québec (Québec) G1V OA6

9 Canada

10

*alice.pradel@univ-rennes1.fr; *julien.gigault@takuvik.ulaval.ca (ORCID : 0000-0002-2988-8942)

\section{ABSTRACT}

The increasing amount of plastic debris in the environment and its disintegration into submicrometric particles is a cause for concern. Due to the colloidal nature of nanoplastics, their environmental fate should be investigated separately from that of microplastics. Abiotic factors greatly influence nanoplastics' stability. This will affect its residence time in the hydrosphere. So, we investigated the behavior of two different nanoplastic models (with different sizes and shapes) regarding ionic strength, $\mathrm{pH}$, and varying concentrations of two natural organic matters: humic acid and sodium alginate. The results demonstrate that both natural organic matters enhanced the aqueous stability of nanoplastics over time at high ionic strengths. Depending on the organic matter's nature, different stabilizing mechanisms were revealed using dynamic light scattering and asymmetrical flow field flow fractionation coupled to static light scattering. Humic acid provides electrostatic repulsion between particles, and some larger humic acid molecules provide a steric hindrance. Sodium alginate sorbs onto and bridges separate particles and small aggregates of nanoplastics. The covered particles are stabilized by steric hindrance. The results highlight the importance of considering natural organic matters' properties when assessing nanoplastics behavior in the environment. 

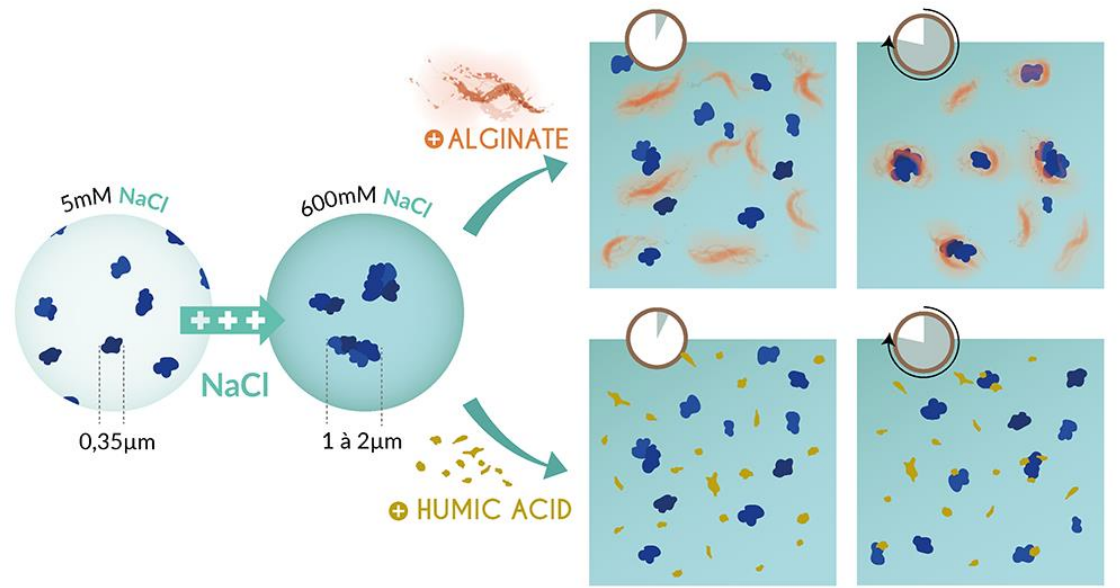

KEYWORDS

29 Plastic debris, Environmental fate, Aggregation, Ionic strength, Morphology

30

SYNOPSIS

32

Mechanisms of nanoplastic stabilization will depend on the composition of the natural organic matter. 


\section{INTRODUCTION}

As the use of plastic-based materials increases, plastic waste in the environment increases proportionally ${ }^{1,2}$. These last five years, it was demonstrated that plastic debris could persist as nanoplastic $(<1 \mu \mathrm{m})$ before eventual mineralization of the polymer ${ }^{3-5}$. Environmental sampling of plastic debris at the ocean surface, coupled to numerical modeling, suggests that a substantial part of all the plastic debris is composed of nanoplastics ${ }^{6-8}$. Since nanoplastics are an emerging contaminant, their environmental fate should be better described. While airborne transport of microplastics is increasingly coming under scrutiny ${ }^{9,10}$, water remains the environmental compartment where most plastic debris is found ${ }^{11,12}$ and where oxidative and hydrolytic conditions are favorable to plastic degradation ${ }^{13-16}$. As such, it is crucial to understand the behavior of nanoplastics in aqueous systems.

To describe a colloidal material's environmental fate in aqueous systems, successive and complementary approaches consist of modeling simple environmental systems in the lab, using these results to establish numerical simulations, and, finally, confronting these simulations with the analysis of environmental samples ${ }^{17}$. Based on this approach, experimental systems describing nanoplastics' fate have emerged ${ }^{18}$, especially concerning porous media ${ }^{19-21}$ and water ${ }^{22,23}$. Nanoplastics' stability in water is generally determined by measuring changes in their size and sedimentation rates. Using this approach, the stability of nanoplastics has been assessed in natural waters ${ }^{23-33}$, in deionized water with various ionic compositions, ionic strengths, and $\mathrm{pHs}^{21,22,25,31,34-40}$, in the presence of NOM and suspended sediments $^{22,23,27,31,33,34,36,38-41}$ and in the presence of extracellular polymeric substances (EPS) ${ }^{37,42}$. Most studies have used polystyrene (PS) latex spheres, which are perfectly smooth, spherical, and monodisperse in size. Recently, the stability of more environmentally relevant models, such as aged polystyrene (PS) latex spheres, laser-ablated PS, or fragmental PET, has been studied ${ }^{37,39,43,44}$.

While these studies allow the emergence of global trends concerning nanoplastic stability, they also have inconsistent conclusions. For example, nanoplastic models have been observed to be both stable and unstable in artificial seawater ${ }^{33,45}$, and in the presence of iron ${ }^{23,34}$. Such discrepancies can be explained first by the physical and chemical properties of the nanoplastics models used (size, shape, surface functionalization, composition, purity, etc.), which are known to strongly affect the behavior of 
colloidal materials. Additionally, nanoplastics are strongly sensitive to the media's properties (type, concentration, and speciation of electrolytes, nature of the organic matter, $\mathrm{pH}$ ). Indeed, according to the relative concentration of spherical PS nanoplastic models, NOM, and cations, opposite behaviors have been observed ${ }^{23,39}$.

In light of these observations, the stability of two nanoplastic models was studied. The first model is a monodisperse polystyrene latex (PSL) sphere. The second model is produced from the mechanically degraded primary microplastic (PS pellets) and, as such, is more environmentally relevant due to its irregular, asymmetrical shape and polydisperse size. NPs' aqueous stability was assessed at different ionic strengths (5 to $770 \mathrm{mmol} \mathrm{L} \mathrm{L}^{-1} \mathrm{NaCl}$ ) and in the presence of varying concentrations $(0.005$ to $140 \mathrm{mg} \mathrm{L}^{-1}$ ) of two NOMs which have different properties: humic acid (HA) and sodium alginate (SA). HA has a relatively compact structure and amphiphilic properties, whereas SA has a more linear structure with hydrophilic properties. HA represents terrestrial organic matter, whereas SA represents marine organic matter and is a significant component of EPS produced by microbial communities ${ }^{46,47}$. It was demonstrated that both NOMs stabilize the environmentally relevant NP model at high ionic strength. However, due to their different physico-chemical properties, the NOMs have different stabilizing mechanisms. These were characterized by asymmetrical flow field flow fractionation coupled to static light scattering (A4F-SLS) and confirmed by dynamic dynamic light scattering (DLS). The present work discusses these mechanisms and their possible implication for the fate of nanoplastics in both terrestrial and marine environments.

\section{EXPERIMENTAL}

\section{Sample preparation}

All aqueous solutions and dispersions were prepared with analytical grade deionized (DI) water (Millipore, 18.2 M $\Omega$ ). A stock solution of $\mathrm{NaCl}$ (solid, LabKem ExtraPure) at $1.80 \mathrm{~mol} \mathrm{~L}^{-1}$ was prepared. The $\mathrm{pH}$ of all solutions was fixed at $\mathrm{pH}$ of 5, 6.5, or 8 using $\mathrm{NaOH}$ (Fisher Scientific, Analytical Grade) and $\mathrm{HCl}\left(70 \%\right.$, Sigma Aldrich, ACS Grade). All solutions and dispersions were stored at $4^{\circ} \mathrm{C}$ in the dark 
before use. Two nanoplastic (NPs) models were used in this study and are described in Table 1 and illustrated in Figure S1. Carboxylated polystyrene latex spheres of $200 \mathrm{~nm}(P S L \mathrm{COOH})$ are purchased from Polysciences $\odot\left(\right.$ Polybead ${ }^{\circledR}$ Carboxylate Orange Dyed Microspheres $0.20 \mu \mathrm{m}$, Warrington USA). A stock dispersion at a concentration of $100 \mathrm{mg} \mathrm{L}^{-1}$ was prepared. A NP model with irregular and polymorphic shapes $(N P T-P)$ was produced by the mechanical abrasion of industrial-grade polystyrene (PS) pellets (Total, Paris, France) as described by El Hadri et al. $(2020)^{48}$. The pellets are composed of primary (-P) PS, which contains no additives and has not been aged. Due to the less stable nature of the NPT-P compared to PSL COOH, the experiments presented here used different batches of NPT-P to avoid a bias brought about by the aging of the stock dispersion. Each batch was produced using PS from the same degradation round. Before each experiment, the size of the nanoplastic dispersions was verified with DLS measurements. Concentration of the stock NPT-P solution was measured with a Total Carbon Analyzer (Shimadzu TOC-V CSH) and varied between 22 and $35 \mathrm{mg} \mathrm{L}^{-1}$. According to the molecular composition of PS, $1 \mathrm{mg} \mathrm{L}^{-1}$ of organic carbon was converted to $1.08 \mathrm{mg} \mathrm{L}^{-1} N P T-P$.

\begin{tabular}{|c|c|c|c|c|c|c|}
\hline \multirow{2}{*}{$\begin{array}{c}\text { Nanoplastic } \\
\text { model }\end{array}$} & \multirow{2}{*}{$\begin{array}{c}\text { z-average } \\
\text { diameter } \\
(\mathrm{nm})\end{array}$} & \multirow{2}{*}{$\begin{array}{l}\text { Polydispersity } \\
\text { Index (PDI) }\end{array}$} & \multirow{2}{*}{$\begin{array}{l}\text { Aspect } \\
\text { ratio* }\end{array}$} & \multicolumn{3}{|c|}{ Zeta potential in $5 \mathrm{mmol} \mathrm{L}^{-1} \mathrm{NaCl}(\mathrm{mV})$} \\
\hline & & & & pH 5 & pH 6.5 & pH 8 \\
\hline PSL COOH & $197 \pm 2$ & $0.03 \pm 0.01$ & $1.02 \pm 0.05$ & $-37.69 \pm 1.91$ & $-38.65 \pm 2.23$ & $-42.80 \pm 2.98$ \\
\hline$N P T-P$ & $339 \pm 7$ & $0.18 \pm 0.03$ & $1.70 \pm 0.57$ & $-31.67 \pm 1.01$ & $-33.54 \pm 2.72$ & $-35.14 \pm 2.13$ \\
\hline
\end{tabular}

$105 *$ Figure S2 illustrates the aspect ratio of NPT-P particles

108 into $0.1 \mathrm{~L}$ DI water and mixing at $350 \mathrm{rpm}$ in a square bottle overnight. The humic acid (HA) used in 109 this work was Leonardite purchased from the International Humic Substance Society (IHSS). The stock 110 solution of HA was prepared by adding $50 \mathrm{mg}$ of Leonardite powder to $0.1 \mathrm{~L}$ of DI water. To solubilize 
the stock solution, $\mathrm{pH}$ was adjusted to 11 (with $\mathrm{NaOH}$ at $0.1 \mathrm{~mol} \mathrm{~L}^{-1}$ ) under continual agitation with a magnetic stirrer. Then, the solution was mixed at $350 \mathrm{rpm}$ for $24 \mathrm{~h}$. $\mathrm{pH}$ was then fixed to either $5,6.5$, or 8 using $0.1 \mathrm{~mol} \mathrm{~L}^{-1} \mathrm{HCl}$. The concentrations of the NOM stock solutions were determined with a Total Carbon Analyzer (Shimadzu TOC-V CSH). According to the NOM's molecular composition, $1 \mathrm{mg} \mathrm{L}^{-1}$ of organic carbon was converted to $1.6 \mathrm{mg} \mathrm{L}^{-1} \mathrm{HA}$ and $2.8 \mathrm{mg} \mathrm{L}^{-1} \mathrm{SA}$.

\section{Size characterization}

Hydrodynamic diameters $\left(\mathrm{d}_{\mathrm{H}}\right)$ were determined by dynamic light scattering (DLS) probe (Vasco-Flex, Cordouan Technologies, Pessac, France). The measured $d_{H}$ of an agglomerating suspension is the average of the $\mathrm{d}_{\mathrm{H}}$ of the individual particles and aggregates, weighted by their scattered light intensities ${ }^{49}$. The backscattered light is collected at a geometric angle of $170^{\circ}$ with respect to the incident beam direction. For time-resolved DLS, each correlation function was accumulated for 60 seconds and were spaced 30 seconds apart. DLS measurements of stock solutions are composed of an average of six measurements of 60 seconds. The z-average hydrodynamic diameter $\left(\mathrm{d}_{\mathrm{zH}}\right)$ was determined by fitting a normal distribution to the raw data using the cumulant algorithm. To analyze the different populations in size present in a dispersion, the Sparse Bayesian learning (SBL) algorithm was used. The distribution of the NPs' gyration radii was measured by static light scattering (DAWN HELEOS 18 Angles, Wyatt Technology) with prior size fractionation using an asymmetrical flow field flow fractionation (A4F, Eclipse 3+, Wyatt Technology, Dernbach, Germany) and a UV-vis absorbance detector (1200 series, Agilent Technologies, France) as a concentration detector at $254 \mathrm{~nm}$. The global method of A4F separation was used. It was previously optimized and described by Gigault et al. $(2017)^{50}$ (see Supplemental Information, S1).

\section{Kinetics of Colloidal Aggregation}

The kinetics of nanoplastic aggregation were determined by measuring the z-average hydrodynamic diameters $\left(\mathrm{d}_{\mathrm{zH}}\right)$ of the dispersions over one hour. A total volume of $3 \mathrm{~mL}$ was prepared by adding $\mathrm{NaCl}$ and DI water to the vial, followed by NOM (when it was studied), and vigorously 
mixing the solution. Finally, the nanoplastic dispersion was added to the vial, marking the beginning of the kinetic study. All kinetic studies were performed in triplicate. The aggregation rate $(\mathrm{k})$ was determined from the slope of the one-hour-long kinetic study, according to equation (1):

$$
\left(\frac{d d_{z H}(t)}{d t}\right)_{t \rightarrow 0} \propto k N_{0}
$$

where $d_{z H}(t)$ is the hydrodynamic diameter of aggregates as a function of time $t$ and $\mathrm{N}_{0}$ is the initial number-based particle concentration. Statistical analyses were operated using one-way ANOVA. Pairwise comparisons of aggregation rates were made using Tukey's method.

At low ionic strengths, electrostatic repulsion between particles is high due to a thick electrical double layer (EDL): the colloidal dispersion is said to be in the reaction-limited aggregation (RLA) regime. As ionic strength increases, electrostatic repulsion decreases, and the aggregation rate increases. At an ionic strength corresponding to the critical coagulation concentration (CCC), the interparticle energy barrier is eliminated, aggregation rate is maximal $\left(\mathrm{k}_{\text {fast }}\right)$, and the diffusion-limited aggregation (DLA) regime is reached. The attachment efficiency $\alpha$ describes aggregation kinetics by normalizing aggregation rates under RLA regime $(\mathrm{k})$ by the DLA regime $\left(\mathrm{k}_{\mathrm{fast}}\right)$ :

$$
\alpha=\frac{k}{k_{\text {fast }}}=\frac{\left(\frac{d D_{z H}(t)}{d t}\right)_{t \rightarrow 0}}{\left(\frac{d D_{z H}(t)}{d t}\right)_{t \rightarrow 0, \text { fast }}}
$$

\section{Derjaguin Landau Verwey Overbeek (XDLVO) theory of colloidal stability}

The total interaction energy as a function of the distance separating the particles, $G^{\text {tot }}(h)$, is calculated as the sum of the Lifshitz-van der Waals attraction, $\mathrm{G}^{\mathrm{LW}}(\mathrm{h})$, the electrical double layer (EDL) repulsion, $G^{\mathrm{EDL}}(\mathrm{h})$, and the Lewis acid-base energy of interaction $\mathrm{G}^{\mathrm{AB}}(\mathrm{h})$. The surface interaction energy was calculated at an ionic strength of $5 \mathrm{mmol} \mathrm{L}^{-1}$. Particle diameters and zeta-potential are presented in Table 1. 

$(1981)^{51}:$

$$
G^{L W}=-\frac{H r_{p 1} r_{p 2}}{6\left(r_{p 1}+r_{p 2}\right) h}\left[1-\frac{b h}{\lambda} \ln \left(1+\frac{\lambda}{b h}\right)\right]
$$

where $\mathrm{H}$ is the Hamaker constant of polystyrene particles interacting through water, equal to $1.2310^{-20}$ $\mathrm{J} ; \mathrm{r}_{\mathrm{p} 1}$ and $\mathrm{r}_{\mathrm{p} 2}$ are the radii of particles 1 and 2, respectively; $\mathrm{b}$ is an empirically defined constant, $\mathrm{b}=5.32$; and $\lambda$ is the characteristic wavelength of the interaction with a value of $\sim 100 \mathrm{~nm}^{52}$.

The electrical double layer repulsion $\mathrm{G}^{\mathrm{EDL}}(\mathrm{h})$ was calculated using the expression proposed by Hogg et al. $(1966)^{53}$ :

$$
G^{E D L}=\pi \varepsilon \frac{r_{p 1} r_{p 2}}{\left(r_{p 1}+r_{p 2}\right)}\left[2 \xi_{p 1} \xi_{p 2} \ln \left(\frac{1+e^{-\kappa h}}{1-e^{-\kappa h}}\right)+\left(\xi_{p 1}^{2}+\xi_{p 2}^{2}\right) \ln \left(1-e^{-2 \kappa h}\right)\right]
$$

where $\varepsilon$ is the permittivity of the medium, equal to $6.9510^{-10} \mathrm{C}^{2} \cdot \mathrm{J}^{-1} \cdot \mathrm{m}^{-1}, \zeta_{\mathrm{p} 1}$, and $\zeta_{\mathrm{p} 2}$ are the surface charges of particles 1 and 2, respectively, approximated by the zeta potential; and $\kappa$ is the inverse of the EDL thickness (Debye Huckel length reciprocal length), determined by the following equation:

$$
\kappa=\left[\frac{e^{2}}{\varepsilon k_{B} T} \sum i z_{i} n_{i}\right]^{2}
$$

where $\mathrm{e}$ is the charge of the electron; $\mathrm{k}_{\mathrm{B}}$ the Boltzmann constant, $\mathrm{T}$ the temperature, $\mathrm{z}_{\mathrm{i}}$ the valency of the ions $\mathrm{i}$, and $\mathrm{n}_{\mathrm{i}}$ the number of ions i per unit volume.

The Lewis acid-base energy of interaction $\mathrm{G}^{\mathrm{AB}}(\mathrm{h})$ of our system is the expression proposed by van Oss $(1993)^{54}$ :

where $\lambda_{A B}$ is the correlation length, chosen as $1.65 \mathrm{~nm}$, according to Valsesia et al. (2018), and $\mathrm{h}_{0}$ is the minimum distance of separation between the particle and the surface, taken as $0.158 \mathrm{~nm}^{55}$. The acidbase potential $\Delta \mathrm{G}^{\mathrm{AB}}{ }_{\mathrm{h}=\mathrm{h} 0}$ is expressed as: 


$$
\Delta G_{\left(h=h_{0}\right)}^{A B}=-2\left(\gamma_{p 1}^{A B}+\gamma_{p 2}^{A B}-2 \sqrt{\gamma_{p 1}^{A B} \gamma_{p 2}^{A B}}\right)
$$

183 With $\gamma_{P 1}^{A B}$ and $\gamma_{P 2}^{A B}$ the polar component of the surface free energy for particles 1 and 2, respectively. $184 \gamma_{P}^{A B}$ was directly quantified using the method by Valsesia et al. (2018) and found to be equal to 33.91 185 and $31.82 \mathrm{~mJ} . \mathrm{m}^{-2}$ for $P S L C O O H$ and $N P T-P$, respectively ${ }^{55}$. 
189
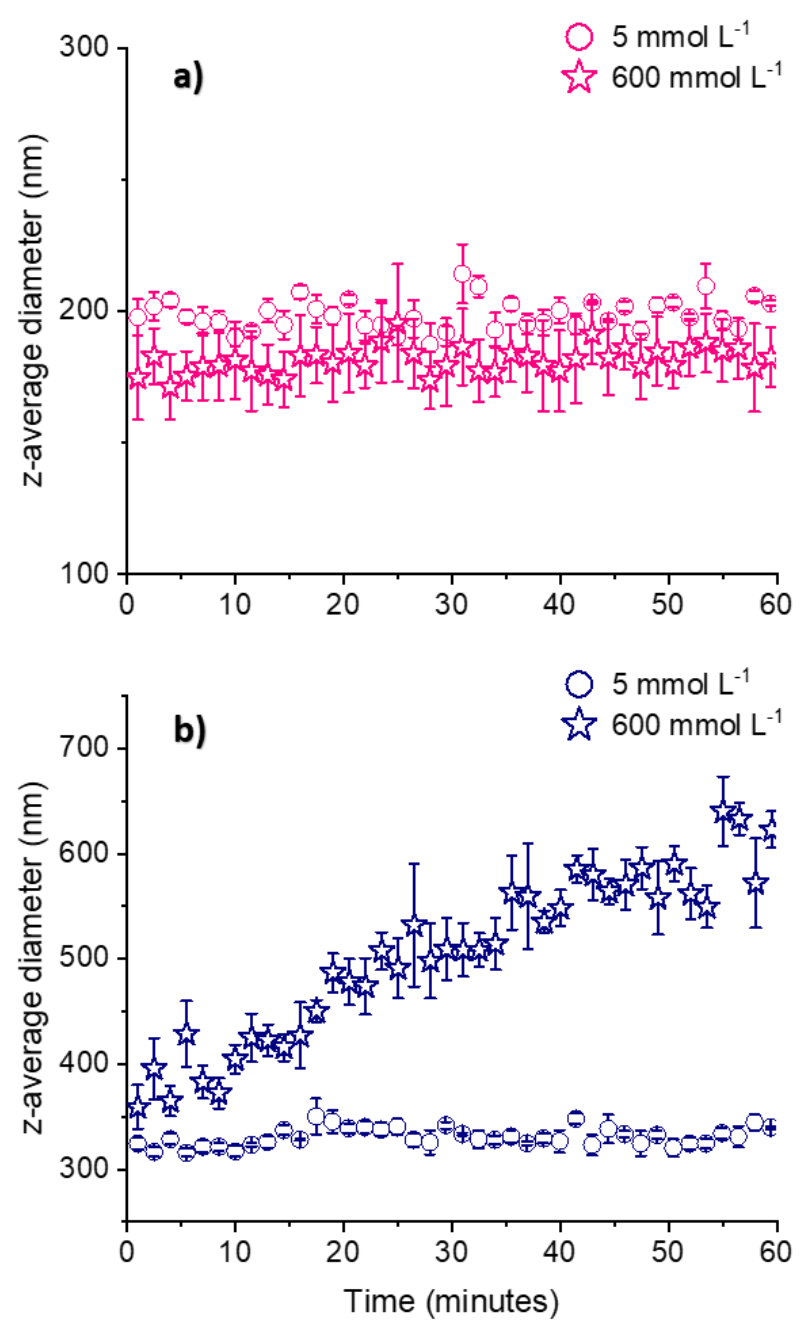

Figure 1: Aggregation kinetics of $4 \mathrm{mg} \mathrm{L}^{-1}$ a) PSL COOH and b) NPT-P in either $5 \mathrm{mmol} \mathrm{L}^{-1}$ or $600 \mathrm{mmol} \mathrm{L}^{-1} \mathrm{NaCl}$ at $\mathrm{pH} 6.5$ $($ Error bar $=$ standard deviation $)$

Figure 1 shows that both particles are stable and low ionic strengths $\left(5 \mathrm{mmol} \mathrm{L}^{-1}\right)$. However, as ionic strength increases, the particles show differences in stability: PSL COOH is stable at high ionic strength $\left(600 \mathrm{mmol} \mathrm{L}^{-1}\right)$, while NPT-P aggregates, with $\mathrm{d}_{\mathrm{zH}}$ increasing from 359 to $623 \mathrm{~nm}$ in one hour. While the aggregation kinetics presented in Figure 1 took place at a $\mathrm{pH}$ of 6.5, the trends in stability were the same at $\mathrm{pH} 5$ and 8, representing the $\mathrm{pH}$ range of natural waters (Figure S3). Based on these kinetics of aggregation, the NPT-P's critical coagulation concentration (CCC) in $\mathrm{NaCl}$ was determined to be 59 and $67 \mathrm{mmol} \mathrm{L}^{-1} \mathrm{NaCl}$ at $\mathrm{pH} 6.5$ and 8, respectively (Fig. S4). These values are lower than the CCC of 260 
mmol L-1 (NaCl, unadjusted $\mathrm{pH})$ previously determined by El Hadri et al. (2020) and show no significant increase in stability with $\mathrm{pH}^{48}$. This suggests that the NPT-P studied here has lower surface oxidation than those studied by El Hadri et al. (2020), as confirmed by a lower zeta (-33 vs. $-44 \mathrm{mV})$. For NPT-P, the concentration of - $\mathrm{COOH}$ on the surface is lower, inhomogeneous, and uncontrolled. The mechanical degradation method used to produce NPT-P cannot control the -COOH functionalization of their surface, which induces possible variability on the CCC. The CCC value of PSL COOH was not assessed since these particles were stable up to $1 \mathrm{M} \mathrm{NaCl}$, which is above environmentally relevant concentrations. The CCC of NPT-P was lower than that of PSL models, as illustrated in Table 2. The reasons behind differences in stability between our PSL and NPT-P models are discussed below. Differences in stability between PSL particles and environmentally relevant nanoplastic models are commonly observed. Indeed, Yu et al. (2019) determined that non-functionalized and carboxylated PSL spheres have a CCC of 310 and $308 \mathrm{mmol} \mathrm{L}^{-1} \mathrm{NaCl}$, respectively ${ }^{39}$. Mao et al. (2020) found an even greater CCC of 591 mmol L ${ }^{-1} \mathrm{NaCl}$ for non-functionalized PSL spheres ${ }^{37}$. The aging of these particles by UV-irradiation strongly oxidized their surface. This caused stronger electrostatic repulsion, and consequently, the CCC increased up to $1108 \mathrm{mmol} \mathrm{L}^{-1}$. Singh et al. (2019) found a lower CCC of $140 \mathrm{mmol} \mathrm{L}^{-1} \mathrm{NaCl}$ for nonfunctionalized PSL and attributed this difference to the removal of surfactants ${ }^{31}$. The CCC calculated for NPT-P was coherent with observations made on other non-spherical, non-emulsified and surfactantfree, nanoplastic models. For example, NPs produced by laser ablation of PS show strong aggregation in $300 \mathrm{mmol} \mathrm{L} \mathrm{L}^{-1} \mathrm{NaCl}^{39}$. NPs produced from mechanical fragmentation polyethylene glycol terephthalate (PET-G) had a CCC of $54 \mathrm{mmol} \mathrm{L}^{-1} \mathrm{NaCl}$ at $\mathrm{pH}$ 6, and $110 \mathrm{mmol} \mathrm{L}{ }^{-1} \mathrm{NaCl}$ at $\mathrm{pH} 10^{43}$. These recent observations confirm that particles' surface functionalization and morphology, as well as the presence of surfactants play key roles in the kinetics of aggregation. 
Table 2: Summary of different critical coagulation concentrations (CCC) of $\mathrm{NaCl}$ for various $\mathrm{NP}$ models

\begin{tabular}{|c|c|c|}
\hline $\begin{array}{l}\text { NPs models studied } \\
\text { Nomenclature : } \\
\text { Composition Type of particle Surface } \\
\text { functionalization* Nominal size (Charge) }\end{array}$ & $\operatorname{CCC}\left(\mathrm{mmol} \mathrm{L}^{-1}\right)$ & Reference \\
\hline PS Latex sphere $N F$ 100nm (-) & 310 in $\mathrm{NaCl}$ at $\mathrm{pH} 7.4$ & \multirow{3}{*}{ Yu et al., $2019\left({ }^{39}\right)$} \\
\hline PS Latex sphere $\mathrm{COOH} 100 \mathrm{~nm}(-)$ & 308 in $\mathrm{NaCl}$ at $\mathrm{pH} 7.4$ & \\
\hline PS Laser ablation $60 \mathrm{~nm}(-)$ & $\begin{array}{l}\text { Not determined. Strong aggregation } \\
\text { in } 300 \mathrm{mmol} \mathrm{L}^{-1} \mathrm{NaCl} \mathrm{pH} 7.4\end{array}$ & \\
\hline PS Latex sphere $N F 100 \mathrm{~nm} \mathrm{(-)}$ & 591 in $\mathrm{NaCl} \mathrm{pH} 7.5$ & \multirow{3}{*}{ Mao et al., $2020\left({ }^{37}\right)$} \\
\hline $\begin{array}{l}\text { PS Latex sphere aged by UV-irradiation } \\
\text { during } 60 \text { hours } N F 100 \mathrm{~nm}(-) * *\end{array}$ & 957 in $\mathrm{NaCl} \mathrm{pH} 7.5$ & \\
\hline $\begin{array}{l}\text { PS Latex sphere aged by UV-irradiation } \\
\text { during } 120 \text { hours } N F 100 \mathrm{~nm}(-) * *\end{array}$ & 1108 in $\mathrm{NaCl} \mathrm{pH} 7.5$ & \\
\hline PS Latex sphere NF 240(-) & 140 in $\mathrm{NaCl} \mathrm{pH} 6$ & Singh et al., $2019\left({ }^{31}\right)$ \\
\hline PET-G Mechanical degradation $500 \mathrm{~nm} \mathrm{(-)}$ & $\begin{array}{l}54 \text { in } \mathrm{NaCl} \text { pH } 6 \\
110 \text { in } \mathrm{NaCl} \text { pH } 10\end{array}$ & Dong et al., $2020\left({ }^{43}\right)$ \\
\hline PS Mechanical degradation $350 \mathrm{~nm} \mathrm{(-)}$ & 260 in $\mathrm{NaCl} \mathrm{pH}$ unadjusted & El Hadri et al., $2020\left({ }^{48}\right)$ \\
\hline PS Mechanical degradation $350 \mathrm{~nm} \mathrm{(-)}$ & 59 in $\mathrm{NaCl}$ pH 6.5 & \multirow{2}{*}{$\begin{array}{l}N P T-P \text { particles studied } \\
\text { here }\end{array}$} \\
\hline PS Mechanical degradation $350 \mathrm{~nm} \mathrm{(-)}$ & 67 in $\mathrm{NaCl}$ pH 8 & \\
\hline
\end{tabular}

To characterize the effect of the particles' properties (size, surface potential, etc.) on their stability, the level of repulsion (energy barrier) between particles can be modeled by the extended Derjaguin Landau Verwey Overbeek (XDLVO) theory. According to the XDLVO theory, the interaction energies between $N P T-P$ and $P S L C O O H$ are not significantly different (Table S1 and Figure S5). This demonstrates that size, surface charge, and hydrophobicity (Table 1), which are used to calculate interaction energy profiles, do not explain differences in stability. Instead, it suggests that NPT$P^{\prime} s$ morphologies and polydispersity (Table 1 and Figure S1), as well as the lack of surfactants in the dispersion, are responsible for the aggregation rates observed. Indeed, particle morphology will affect their attachment efficiency. $N P T-P$ has an aspect ratio of $1.70 \pm 0.57$ and asperities on their surface, whereas $P S L C O O H$ has an aspect ratio of $1.02 \pm 0.05$ and a smooth surface. At close approach, particles with elongated shapes (high aspect ratios) have larger van der Waals attraction when their major axii face each other ${ }^{56}$. While this has been difficult to demonstrate experimentally ${ }^{57}$, a few aggregation experiments support this theory ${ }^{43,58}$. Also, the collision of irregular and rough particles is likely to occur between particle protrusions and edges ${ }^{59}$. 
For this reason, it is more accurate to model the interaction energy between NPT-P and asperities, using the smallest radius of curvature as the asperity radius ${ }^{60}$. This significantly reduces the level of repulsion (Fig. S5) since the final volume of interaction is reduced and repulsive forces (electrostatic and acid-base) decay more quickly with distance than attractive forces (Lifshitz-van der Waals) ${ }^{61,62}$. Secondly, particle collision rate during perikinetic aggregation (i.e., induced by collisions driven by the Brownian motion) is always more significant for dispersions containing different particle sizes $^{63}$. Finally, NPT-P particles are free of surfactants, which have a stabilizing effect ${ }^{63,64}$. Since the more environmentally relevant nanoplastic model, NPT-P, is not stable at high ionic strengths, the stabilizing effect of natural organic matters (NOMs) was studied.

\section{Stabilization of NPT-P by natural organic matters}

Two different NOMs were chosen to represent the wide variety of physico-chemical properties of naturally occurring organic matters. The interaction of the NPT-P with the natural organic matter was described by characterizing the size of NPT-P with NOM at high ionic strength. Asymmetrical flow field-flow fractionation coupled to static light scattering (A4F-SLS) was used to characterize the assembly of NPT-P with NOM as this technique can discriminate different size populations and changes in polydispersity. Figure 2 illustrates the fractograms obtained for NPT-P in the presence of HA (Fig 2a) and SA (Fig. 2b). NPT-P and HA alone have similar times of elution and variation of their radii of gyration $\left(\mathrm{R}_{\mathrm{g}}\right)$ over time. For NPT-P with HA, the peak's elution time range is identical, suggesting that NPT-P and HA stay dispersed and retain their initial sizes. However, the maximum of the peak increases from 26 to 28 minutes, with the corresponding $\mathrm{R}_{\mathrm{g}}$ increasing from $100 \mathrm{~nm}$ up to $270 \mathrm{~nm}$. This shift suggests that a specific size fraction of HA is associated with NPT-P and formed larger heteroaggregates. Concerning the mixture of NPT-P with SA (Figure 3b), no fractograms were obtained for SA in these fractionation conditions due to its low scattering properties at this concentration $\left(57 \mathrm{mg} \mathrm{L}^{-1}\right)$. In the presence of SA, two peaks are observed: one eluted around 23 minutes and another around 26 minutes. The first peak corresponds to a $\mathrm{R}_{\mathrm{g}}>400 \mathrm{~nm}$, while the second corresponds to a smaller $\mathrm{R}_{\mathrm{g}}$, around $250 \mathrm{~nm}$. In A4F, the normal elution mode occurs when the relative diffusion between the different populations through the channel's height allows their separation according to the parabolic 
profile of the main velocity flow. However, an earlier peak with a high $\mathrm{R}_{\mathrm{g}}$ is indicative of steric elution mode ${ }^{65}$. In this mode, the particles become too large to be separated based on diffusion coefficient and are instead eluted by dragging forces. This first peak, in steric mode, corresponds to SA bridging separate NPT-P particles and sorbing onto small aggregates of NPT-P. The second peak overlaps with that of NPT-P alone and can be explained by the association of SA with single NPT-P or smaller aggregates.
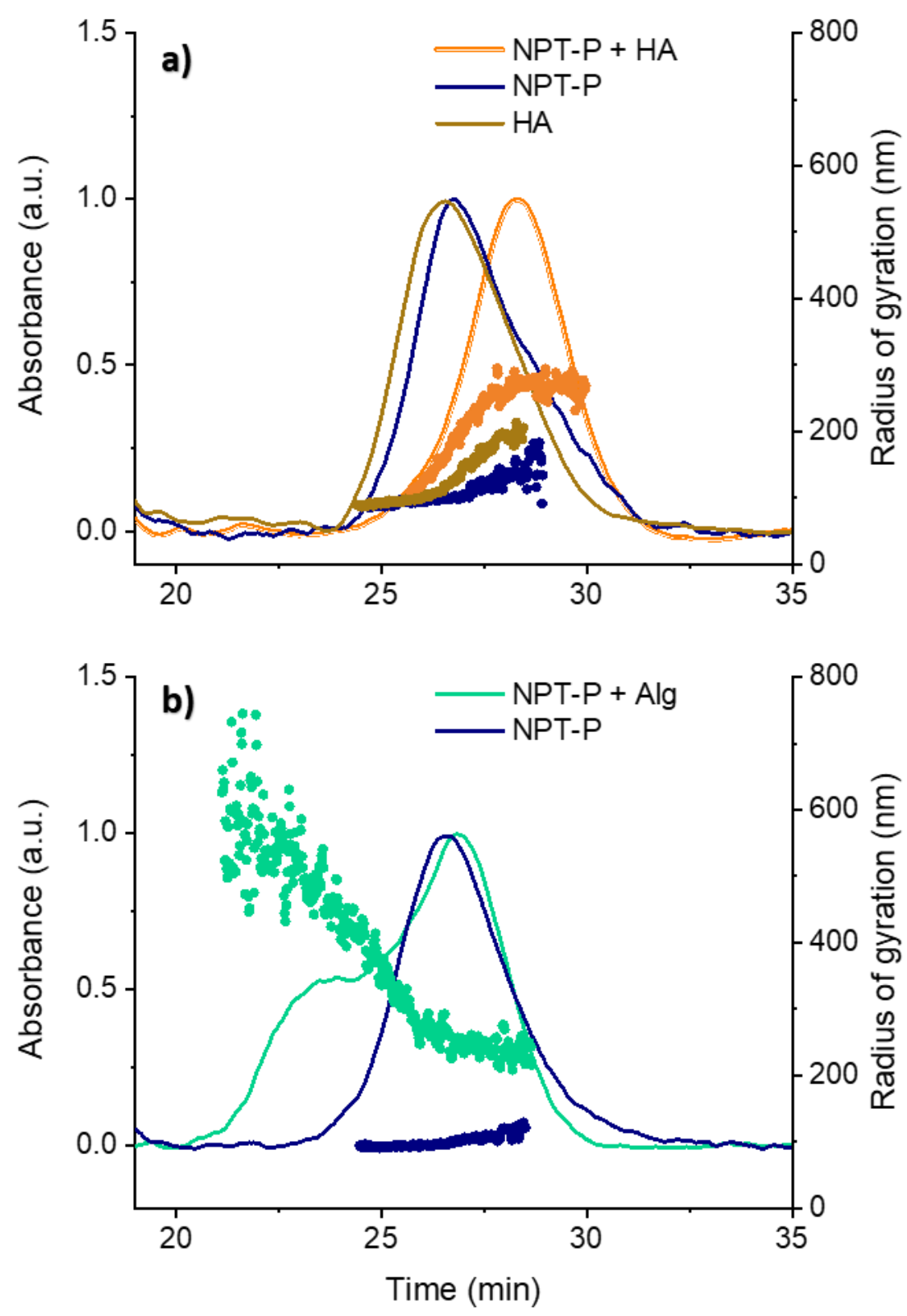
To validate the variations in size populations and distributions, Figure 3 shows the size distributions of NPT-P with HA and with SA at high ionic strength based on the Sparse Bayesian

Learning (SBL) algorithm. This algorithm allows investigating differences in size population within the limits of the DLS resolution. With HA, the NPT-P size distribution is large but still covering the size range of the initial NPT-P. However, HA induces a shift towards a higher $\mathrm{d}_{\mathrm{H}}$ of $530 \mathrm{~nm}$ compared to the initial $\mathrm{d}_{\mathrm{H}}$ of $320 \mathrm{~nm}$ for NPT-P alone. This shift may be due to the non-covalent adsorption of larger HA molecules onto the NPT-P surface. In the presence of SA, the size distribution is less polydisperse but with a maximum $\mathrm{d}_{\mathrm{H}}$ around $820 \mathrm{~nm}$. This larger size population can be explained by the physical association of SA with several (n> 2) NPT-P particles.

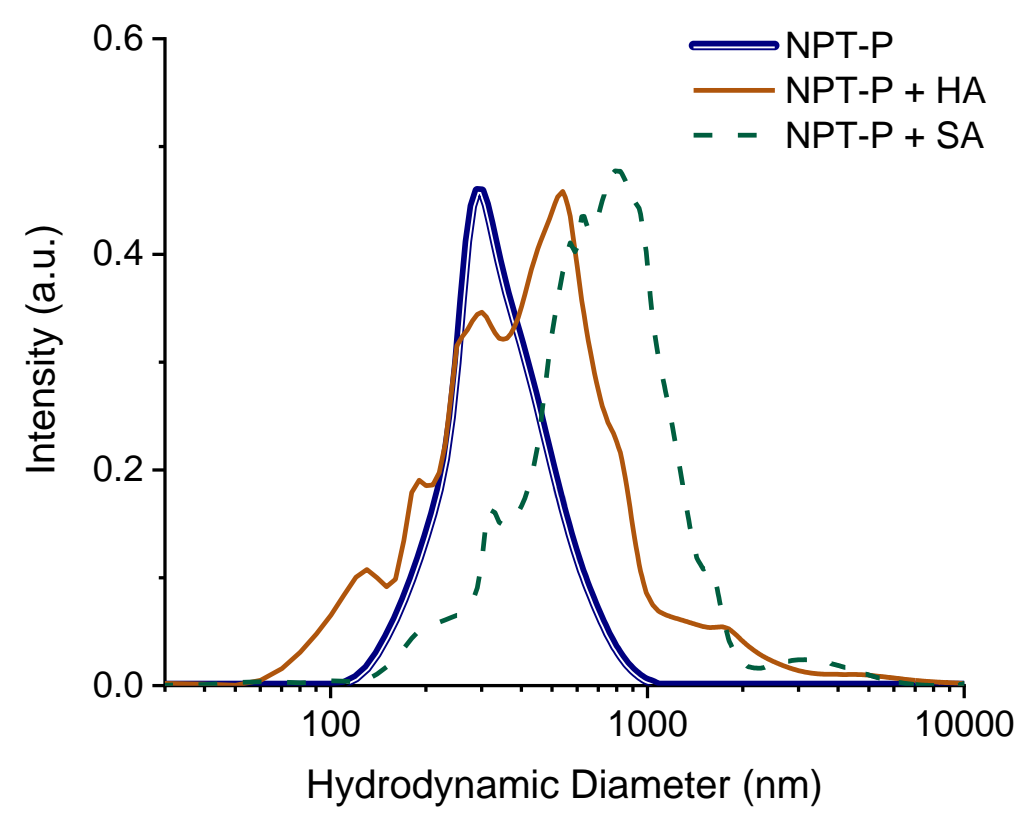

Figure 3: Average of intensity-based size distributions according to SBL algorithm of NPT-P with $30 \mathrm{mg} \mathrm{L}^{-1}$ humic acid (HA) at pH 6.5 or $57 \mathrm{mg} \mathrm{L}^{-1}$ sodium alginate (SA) at pH 8, in $600 \mathrm{mmol} \mathrm{L} \mathrm{L}^{-1} \mathrm{NaCl}$ measured between 45 and 60 minutes $(n \geq 18)$. The SBL algorithm reveals the most probable continuous size distribution among a set of 25 solutions.

The A4F-SLS fractograms and DLS size distributions (Figures 2 and 3) suggest that HA and SA have different stabilization mechanisms. On the one hand, the HA molecules that are free in solution stabilize NPT-P by providing electrostatic repulsion. Some low molecular weight HA molecules are also adsorbing onto the NPT-P surface and providing steric repulsion. The co-occurrence of these two mechanisms is supported by the fact that leonardite humic acid is one of the more large and polydisperse 
humic acids ${ }^{66}$. Indeed, electrostatic repulsion is attributed to the smaller size fraction of humic and fulvic $\operatorname{acids}^{38,40}$, while surface adsorption of the larger size fraction of HAs may occur via $\pi-\pi$ interactions (with the aromatic structures of HA) and result in steric hindrance ${ }^{22,31,39,67}$. Saavedra et al. (2019) noted that both $\mathrm{HA}$ and $\mathrm{SA}^{41}$ stabilized negatively charged particles. Due to HA's compact structure, adsorption of HA onto colloids did not increase their size. However, SA's high molecular weight (282 kDa, Fig. S6) and semi-rigid chains can lead to the formation of larger aggregates ${ }^{17}$. Indeed, SA chains stabilize NPT-P particles by wrapping around single particles and small aggregates and bridging separate particles. These hetero-aggregates are then prevented from further aggregating by steric hindrance. Since SA is highly hydrophilic, its adsorption onto nanoplastics can be attributed to hydrogen bonds and van der Waals interactions ${ }^{42,46,68,69}$. Indeed, Bhattacharya et al. (2010) demonstrated a significant affinity between negatively charged carboxylated PSL and negatively charged algae ${ }^{70}$. This affinity has been attributed to hydrogen bonds forming between the cellulosic component of algae and the PSL. Finally, using TEM, it appears that NPT-P is embedded in SA, while HA does not seem to have such a strong affinity with the NPT-P surface (Fig. S7).

\section{Colloidal stability of NPT-P according to the nature and concentrations of NOM}

These two mechanisms of stabilization will have distinct impacts on nanoplastics' colloidal stability in aqueous media. Figure 4 illustrates the size variation of NPT-P in $600 \mathrm{mmol} \mathrm{L}^{-1} \mathrm{NaCl}$ with either $\mathrm{HA}$ or SA. At $600 \mathrm{mmol} \mathrm{L}^{-1} \mathrm{NaCl}$, the size of NPT-P increases in the absence of NOM (Fig. 1). Figure 4 shows that HA can stabilize NPT-P immediately, while SA stabilizes NPT-P within 10 minutes. The final sizes obtained (i.e., $300 \mathrm{~nm}$ for $\mathrm{HA}$ and $560 \mathrm{~nm}$ for SA) corroborate that different interactions occur between NPT-P and the two NOMs. In the presence of HA, the $\mathrm{d}_{\mathrm{zH}}$ of NPT-P remains constant around $300 \mathrm{~nm}$. HA is highly polydisperse with a colloidal fraction centered around $230 \mathrm{~nm}$. So, for kinetics of NPT-P with HA, the $\mathrm{d}_{\mathrm{zH}}$ presented in Figure 4 is a combination of both the $\mathrm{d}_{\mathrm{zH}}$ of NPT-P (339 nm) and the $\mathrm{d}_{\mathrm{zH}}$ of HA $(230 \mathrm{~nm})$. Despite this significant contribution of HA to the DLS signal, DLS will rapidly detect if aggregation occurs since scattering is highly sensitive to increases in size ${ }^{71}$. 
In the presence of SA, the size of NPT-P increases within the first 10 minutes and stabilizes around 560 nm. Without NOM, such an increase in size takes more than 30 minutes (Fig. 1).

Contrary to HA, $57 \mathrm{mg} \mathrm{L}^{-1} \mathrm{SA}$ does not contribute to the DLS signal. Therefore this increase in size followed by a stabilization is explained by a rapid hetero-association between NPT-P (particles and/or aggregates) and SA. Instead of keeping all particles separate as HA does, the SA biopolymer wraps separate or slightly aggregated plastic nanoparticles. Alginate molecules have been observed to form a layer with an approximate thickness of $20 \mathrm{~nm}$ around positively charged PSLs ${ }^{23}$. Also, when studying the aggregation of NPs with the dissolved $(<0.22 \mu \mathrm{m})$ fraction of organic matter that is naturally present in seawater, Chen et al. (2018) obtained similar kinetics of hetero-aggregation, with a rapid increase in size followed by a plateau around micrometric sizes ${ }^{68}$.

The relative quantity of particles and aggregates present in the dispersions over time was estimated based on the hydrodynamic diameter $\left(\mathrm{d}_{\mathrm{zH}}\right)$, the intensity of scattered light $\left(\mathrm{I}_{\theta}\right)$, and a spherical form factor $\left(\mathrm{P}_{\theta}\right)$, as described in Supplemental Information (S7). At high ionic strength, results show that the relative concentration of NPT-P plummets without NOM (Fig. S8). The relative NPT-P particle concentration does not decrease in the presence of HA, indicating colloidal stabilization induced by electrostatic repulsion. On the contrary, with SA, the relative NPT-P particle concentration decreases significantly and then stabilizes. Such behavior can be explained by the hetero-association of SA with NPT-P leading to a final state where all the NPT-P are associated with SA. Consequently, the rate of collision is reduced because of (i) the low rate of diffusion of large aggregates, (ii) the reduced number of separate particles and aggregates, and (iii) the effective repulsion between SA-coated surfaces. 


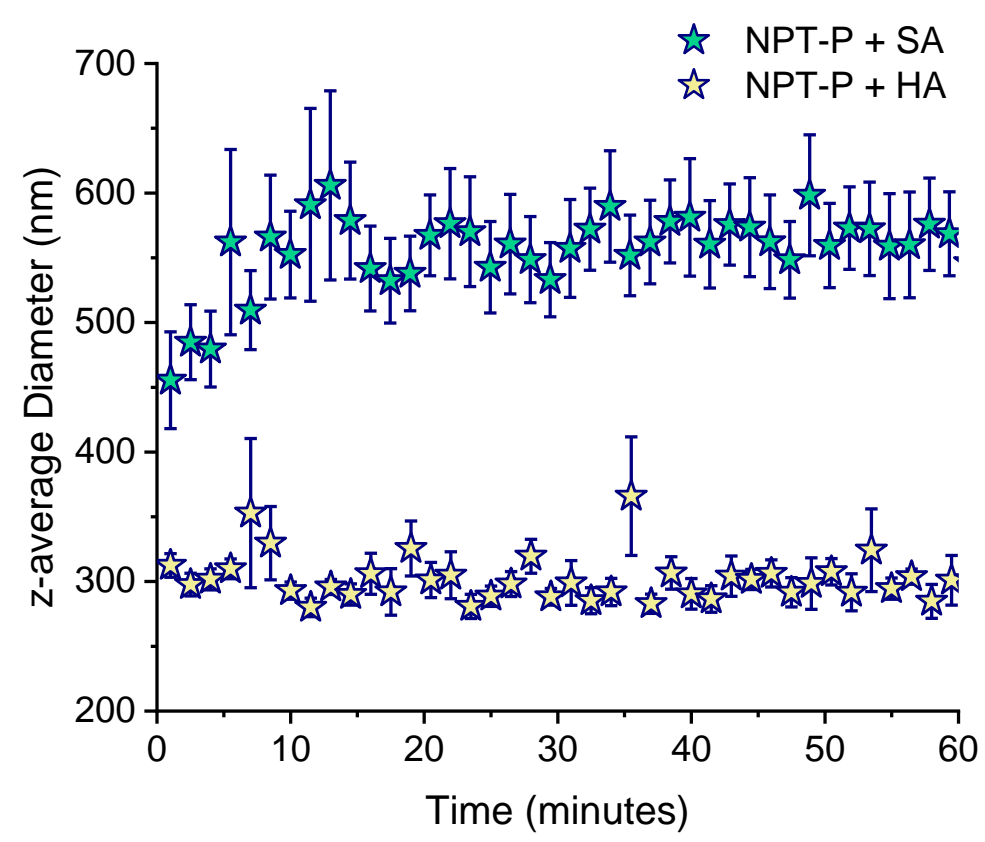
and $30 \mathrm{mg} \mathrm{L}^{-1}$ humic acid $(H A)$ at $\mathrm{pH} 6.5$ (Error bar = standard deviation)

$\mathrm{NaCl}$ and $\mathrm{NOM}$ concentration. Due to the nature of the kinetics of aggregation of NPT-P/SA in the presence of SA, two different slopes were compared: $\mathrm{k}_{0-10}$, which represents the fast rate of aggregation from 0 to 10 minutes, and $\mathrm{k}_{10-60}$ representing the plateau, observed from 10 to 60 minutes. Figure $5 \mathrm{a}$ shows that NPT-P and SA's association is always faster than the homo-aggregation of NPT-P for the whole range of the ionic strength investigated (5 to $770 \mathrm{mmol} \mathrm{L}^{-1}, \mathrm{pH}$ 8). So, the aggregation kinetics are initially accelerated by SA, which sorbs onto and bridges NPT-P particles. Figure $5 \mathrm{~b}$ shows no significant increase in the rate of the initial, fast aggregation rate $\left(\mathrm{k}_{10-60}\right)$ as a function of SA concentration. This suggests that small SA concentrations are sufficient to cover and stabilize NPT-P. The SA that remains free in the solution (non-adsorbed) may have a stabilizing effect by increasing the solution's electrostatic repulsion. This agrees with Summers et al. (2018), who observed that a low concentration $\left(\leq 1 \mathrm{mg} \mathrm{L}^{-1}\right)$ of EPS in a nanoplastic dispersion could play a dispersant effect ${ }^{42}$.

Figure 5c presents the aggregation rate of $N P T-P$ with NOM as a function of ionic strength during the stable section of aggregation's kinetics. In the presence of NOM, all aggregation rates were 
lower than without $\mathrm{NOM}$, except at $5 \mathrm{mmol} \mathrm{L}^{-1} \mathrm{NaCl}$, where there was no significant difference (Fig.

$3625 \mathrm{c}$ and S3). In the presence of HA, NPT-P's aggregation rate is not significantly different from $0 \mathrm{~nm}$ $363 \min ^{-1}$ except at 26 and $770 \mathrm{mmol} \mathrm{L}^{-1}(\mathrm{p}<0.05)$. At $770 \mathrm{mmol} \mathrm{L}^{-1}$, the aggregation rate increases, 364 suggesting that HA is losing its stabilizing effect due to a strong electrostatic screening by this high 365 ionic strength. In the presence of SA, the aggregation rate hovers around $0.4 \mathrm{~nm} \mathrm{~min}^{-1}$, especially at 366 higher ionic strengths. This suggests that HA may have a stronger stabilizing effect than SA. The NOM 367 concentration in Fig. 5c was the minimum concentration required best stabilize the nanoplastic models 368 at $600 \mathrm{mmol} \mathrm{L}^{-1} \mathrm{NaCl}$ (cf: Fig. 5d). Figure 5d shows that at high ionic strength HA rapidly reduces 369 NPT-P's attachment efficiency. This is supported by the observations made by Singh et al. (2019), 370 indicating that low concentrations of HA increased the CCC of negatively charged PSL spheres almost 3714 -fold ${ }^{31}$. However, even high SA concentrations do not reduce $\mathrm{k}_{10-60}$ under $0.6 \mathrm{~nm} \mathrm{~min}^{-1}$. This agrees 372 with Summers et al. (2018), who show that high alginate concentrations can have a flocculant effect ${ }^{42}$. Furthermore, Lodeiro et al. (2016) noted that SA only slightly increased the stability of silver 374 nanoparticles ${ }^{72}$. Saleh et al. (2010) also noted that HA was more effective than SA at stabilizing carbon 375 nanotubes in $\mathrm{NaCl}^{73}$. The slightly more effective stabilizing capacity of $\mathrm{HA}$ compared to SA can be 376 attributed to the fact that SA sorbs onto particles while HA causes repulsion between them. Indeed, the 377 first mechanism is more likely to form flocs that are large enough to be affected by gravity. 

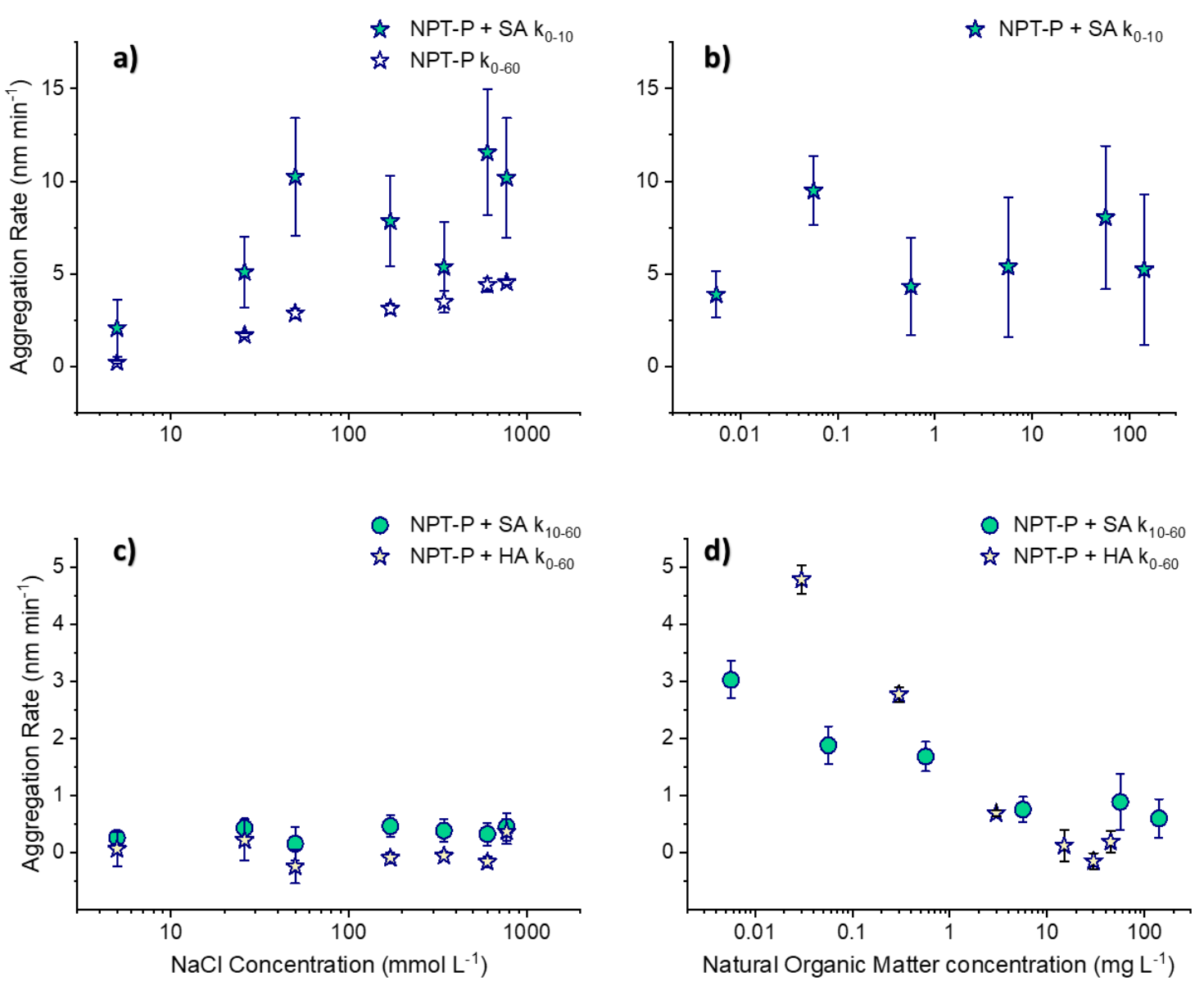

Figure 5: a) Aggregation rate of NPT-P and fast aggregation rate ( $\left.k_{0-10}\right)$ of NPT-P with $57 \mathrm{mg} \mathrm{L}^{-1}$ SA, at $\mathrm{pH} 8$ as a function of $\mathrm{NaCl}$ concentration b) fast aggregation rate ( $\left.k_{0-10}\right)$ of NPT-P with varying concentrations of SA at $600 \mathrm{mmol} \mathrm{L}^{-1} \mathrm{NaCl}$ and $\mathrm{pH}$ 8. Aggregation rates of NPT-P with c) $57 \mathrm{mg} \mathrm{L}^{-1} \mathrm{SA}\left(\mathrm{k}_{10-60}\right)$ at $\mathrm{pH} 8$ and with $30 \mathrm{mg} \mathrm{L}^{-1} \mathrm{HA}\left(\mathrm{k}_{0-60}\right)$ at $\mathrm{pH} 6.5$ as a function of $\mathrm{NaCl}$ and d) in $600 \mathrm{mmol}^{-1} \mathrm{NaCl}$, with varying concentrations of $\mathrm{HA}$ at $\mathrm{pH} 6.5$ and different concentrations of SA at pH 8.

\section{Environmental Implications of NOM-NP interactions} performed at $\mathrm{pH} 5,6.5$, and 8 for both NOMs show that the same stabilizing mechanisms operate in the $\mathrm{pH}$ range of natural waters (Fig. S9). At a given ionic strength, aggregation rates did not significantly differ with $\mathrm{pH}(\mathrm{p}<0.05)$. This minimal $\mathrm{pH}$-dependency is to be expected since (i) NPT-P's stability is not $\mathrm{pH}$-dependent, (ii) HA stabilizes these particles by electrostatic and steric repulsion, which only requires the NOM to be significantly negatively charged and unfolded, (iii) SA stabilizes NPT-P by 
The different stabilizing mechanisms are summarized in Figure 6. These mechanisms have been shown to stabilize natural colloids ${ }^{17}$ as well as engineered nanomaterials ${ }^{73-77}$. When studying the stability of fullerene, Espinasse et al. (2007) also noted the different mechanisms of stabilization of HA and SA ${ }^{74}$. Fullerene were more water-soluble in the presence of HA. HA's combination of hydrophobic regions and ionizable functional groups allows the former to sorb to hydrophobic particles and the latter to increase the particle's hydrophilicity. The amount of HA sorption onto carbon nanotubes was proportional to the HA aromaticity ${ }^{75}$. So, HA increases particles' stability by steric and charge stabilization. However, SA's large size promoted the aggregation of stable, polar fullerenes by bridging and encapsulating them ${ }^{74}$. Indeed, in $\mathrm{NaCl}$, SA coats positively charged titanium dioxide and hematite nanoparticles which then confers electrostatic stability ${ }^{76,77}$. SA also coats and stabilizes negatively charged, carbonaceous nanomaterials, such as single-walled carbon nanotubes ${ }^{73}$.

In aqueous media, we might expect that SA will stabilize NPs and increase their dispersal. At the same time, it will induce retention when it is attached to a solid interface (i.e., soils, sediments, etc.) $)^{69,74}$. Furthermore, Cunha et al. (2020) showed that nanoplastics and microplastics' presence enhanced the production of EPS carbohydrates by freshwater Cyanothece sp., suggesting a feedbackloop may occur ${ }^{78}$. The presence of NOM will impact nanoplastics environmental fate and affect the potential for co-transport of contaminants ${ }^{79,80}$. For example, compared to a matrix containing only a nanoplastic model and hydrophobic organic compounds (HOCs), the addition of HA to the matrix increased Daphnia magna's rate of uptake of the HOCs by ingestion ${ }^{81}$. 


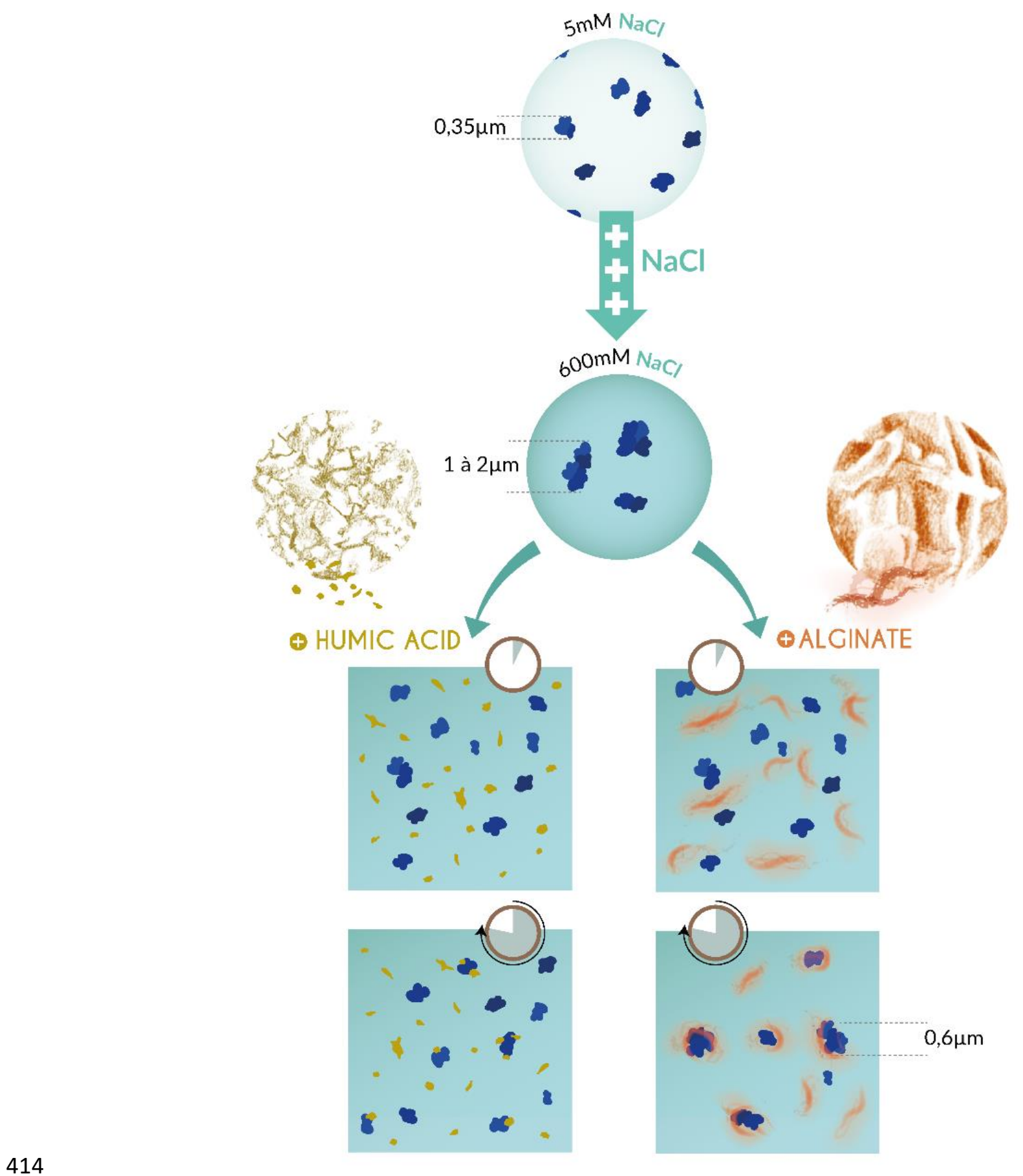

415 Figure 6: Summary of the mechanisms of stabilization of NPT-P by humic acid (HA) and sodium alginate (SA) in NaCl 


\section{CONCLUSION}

419 This study investigated the mechanisms of stabilization of nanoplastics by natural organic matter (NOM)

420 according to the media's ionic strength. The interaction of the nanoplastics with NOMs was determined 421 by characterizing the size distributions and shapes using asymmetrical flow field-flow fractionation 422 coupled to static light scattering (A4F-SLS) and confirmed by dynamic light scattering (DLS). 423 According to their origin, the different NOM models, i.e., sodium alginate (SA) for marine environments 424 and humic acid (HA) for terrestrial ones, present different stabilization mechanisms. Humic acid 425 stabilizes the nanoplastic dispersion by electrostatic repulsion between particles, while larger molecules 426 may sorb onto nanoplastics and provide a steric hindrance. However, sodium alginate adsorbs onto the 427 nanoplastics' surface and bridges particles to form small aggregates that remain stable by steric 428 hindrance against the increase in ionic strength. This study highlights the need to consider NOM's physico-chemical properties when assessing nanoplastics behavior in the aqueous environment. 
431 Images and size description of the nanoplastics models (Figure S1 and S2, pages S2-S3); Description of 432 the asymmetrical field flow fractionation method (Section S1, page S4); Aggregation rates and Critical 433 Coagulation Concentrations of the nanoplastics in $\mathrm{NaCl}$ (Figure S3 and S4); Results of the Extended 434 Derjaguin Landau Verwey Overbeek (XDLVO) model (Table S1 and Figure S5, page S7,); 435 Characterization of the sodium alginate (Figure S6, text page S8); Images of nanoplastics in the presence 436 of natural organic matter (Figure S7 and text page S9); Evolution of nanoplastics concentration 437 according to time calculated from static light scattering (Figure S8, text page S10 and S11); Aggregation 438 kinetics of nanoplastics models in the presence of natural organic matter (Figure S9, page S12). This 439 material is available free of charge via the internet at http://pubs.acs.org.

440

441 ACKNOWLEDGEMENTS

442 We acknowledge Julie Borgese for the illustrations and Ludivine Rault for the TEM images. 


\section{REFERENCES}

(1) Geyer, R.; Jambeck, J. R.; Law, K. L. Production, Use, and Fate of All Plastics Ever Made. Science Advances 2017, 3 (7), e1700782. https://doi.org/10.1126/sciadv.1700782.

(2) Jambeck, J. R.; Geyer, R.; Wilcox, C.; Siegler, T. R.; Perryman, M.; Andrady, A.; Narayan, R.; Law, K. L. Plastic Waste Inputs from Land into the Ocean. Science 2015, 347 (6223), 768-771. https://doi.org/10.1126/science.1260352.

(3) Gigault, J.; Pedrono, B.; Maxit, B.; Halle, A. T. Marine Plastic Litter: The Unanalyzed NanoFraction. Environ. Sci.: Nano 2016, 3 (2), 346-350. https://doi.org/10.1039/C6EN00008H.

(4) Lambert, S.; Wagner, M. Characterisation of Nanoplastics during the Degradation of Polystyrene. Chemosphere 2016, 145, 265-268. https://doi.org/10.1016/j.chemosphere.2015.11.078.

(5) Zhu, L.; Zhao, S.; Bittar, T. B.; Stubbins, A.; Li, D. Photochemical Dissolution of Buoyant Microplastics to Dissolved Organic Carbon: Rates and Microbial Impacts. Journal of Hazardous Materials 2019, 121065. https://doi.org/10.1016/j.jhazmat.2019.121065.

(6) Koelmans, A. A.; Kooi, M.; Law, K. L.; van Sebille, E. All Is Not Lost: Deriving a Top-down Mass Budget of Plastic at Sea. Environmental Research Letters 2017, 12 (11), 114028. https://doi.org/10.1088/1748-9326/aa9500.

(7) Ter Halle, A.; Jeanneau, L.; Martignac, M.; Jardé, E.; Pedrono, B.; Brach, L.; Gigault, J. Nanoplastic in the North Atlantic Subtropical Gyre. Environmental Science \& Technology 2017, 51 (23), 13689-13697. https://doi.org/10.1021/acs.est.7b03667.

(8) van Sebille, E.; Wilcox, C.; Lebreton, L.; Maximenko, N.; Hardesty, B. D.; van Franeker, J. A.; Eriksen, M.; Siegel, D.; Galgani, F.; Law, K. L. A Global Inventory of Small Floating Plastic Debris. Environmental Research Letters 2015, 10 (12), 124006. https://doi.org/10.1088/17489326/10/12/124006.

(9) Allen, S.; Allen, D.; Phoenix, V. R.; Le Roux, G.; Durántez Jiménez, P.; Simonneau, A.; Binet, S.; Galop, D. Atmospheric Transport and Deposition of Microplastics in a Remote Mountain Catchment. Nature Geoscience 2019. https://doi.org/10.1038/s41561-019-0335-5.

(10) Evangeliou, N.; Grythe, H.; Klimont, Z.; Heyes, C.; Eckhardt, S.; Lopez-Aparicio, S.; Stohl, A. Atmospheric Transport Is a Major Pathway of Microplastics to Remote Regions. Nat Commun 2020, 11 (1), 3381. https://doi.org/10.1038/s41467-020-17201-9.

(11) GESAMP. Sources, Fate and Effects of Microplastics in the Marine Environment: Part Two of a Global Assessment. 2016, No. 93, 220.

(12) Horton, A. A.; Walton, A.; Spurgeon, D. J.; Lahive, E.; Svendsen, C. Microplastics in Freshwater and Terrestrial Environments: Evaluating the Current Understanding to Identify the Knowledge Gaps and Future Research Priorities. Science of The Total Environment 2017, 586, 127-141. https://doi.org/10.1016/j.scitotenv.2017.01.190.

(13) Chamas, A.; Moon, H.; Zheng, J.; Qiu, Y.; Tabassum, T.; Jang, J. H.; Abu-Omar, M.; Scott, S. L.; Suh, S. Degradation Rates of Plastics in the Environment. ACS Sustainable Chem. Eng. 2020, acssuschemeng.9b06635. https://doi.org/10.1021/acssuschemeng.9b06635. 
(14) Gewert, B.; Plassmann, M. M.; MacLeod, M. Pathways for Degradation of Plastic Polymers Floating in the Marine Environment. Environmental Science: Processes \& Impacts 2015, 17 (9), 15131521. https://doi.org/10.1039/C5EM00207A.

(15) Julienne, F.; Delorme, N.; Lagarde, F. From Macroplastics to Microplastics: Role of Water in the Fragmentation of Polyethylene. Chemosphere 2019, 236, 124409.

https://doi.org/10.1016/j.chemosphere.2019.124409.

(16) Min, K.; Cuiffi, J. D.; Mathers, R. T. Ranking Environmental Degradation Trends of Plastic Marine Debris Based on Physical Properties and Molecular Structure. Nat Commun 2020, 11 (1), 727. https://doi.org/10.1038/s41467-020-14538-z.

(17) Buffle, J.; Wilkinson, K. J.; Stoll, S.; Filella, M.; Zhang, J. A Generalized Description of Aquatic Colloidal Interactions: The Three-Colloidal Component Approach. Environ. Sci. Technol. 1998, 32 (19), 2887-2899. https://doi.org/10.1021/es980217h.

(18) Alimi, O. S.; Farner Budarz, J.; Hernandez, L. M.; Tufenkji, N. Microplastics and Nanoplastics in Aquatic Environments: Aggregation, Deposition, and Enhanced Contaminant Transport.

Environmental Science \& Technology 2018, 52 (4), 1704-1724.

https://doi.org/10.1021/acs.est.7b05559.

(19) Dong, Z.; Zhu, L.; Zhang, W.; Huang, R.; Lv, X.; Jing, X.; Yang, Z.; Wang, J.; Qiu, Y. Role of Surface Functionalities of Nanoplastics on Their Transport in Seawater-Saturated Sea Sand. Environmental Pollution 2019, 255, 113177. https://doi.org/10.1016/j.envpol.2019.113177.

(20) Keller, A. S.; Jimenez-Martinez, J.; Mitrano, D. M. Transport of Nano- and Microplastic through Unsaturated Porous Media from Sewage Sludge Application. Environ. Sci. Technol. 2019, acs.est.9b06483. https://doi.org/10.1021/acs.est.9b06483.

(21) Liu, J.; Zhang, T.; Tian, L.; Liu, X.; Qi, Z.; Ma, Y.; Ji, R.; Chen, W. Aging Significantly Affects Mobility and Contaminant-Mobilizing Ability of Nanoplastics in Saturated Loamy Sand. Environ. Sci. Technol. 2019, acs.est.9b00787. https://doi.org/10.1021/acs.est.9b00787.

(22) Li, Y.; Wang, X.; Fu, W.; Xia, X.; Liu, C.; Min, J.; Zhang, W.; Crittenden, J. C. Interactions between Nano/Micro Plastics and Suspended Sediment in Water: Implications on Aggregation and Settling. Water Research 2019, 161, 486-495. https://doi.org/10.1016/j.watres.2019.06.018.

(23) Oriekhova, O.; Stoll, S. Heteroaggregation of Nanoplastic Particles in the Presence of Inorganic Colloids and Natural Organic Matter. Environ. Sci.: Nano 2018, 5 (3), 792-799. https://doi.org/10.1039/C7EN01119A.

(24) Bergami, E.; Krupinski Emerenciano, A.; González-Aravena, M.; Cárdenas, C. A.; Hernández, P.; Silva, J. R. M. C.; Corsi, I. Polystyrene Nanoparticles Affect the Innate Immune System of the Antarctic Sea Urchin Sterechinus Neumayeri. Polar Biol 2019, 42 (4), 743-757. https://doi.org/10.1007/s00300-019-02468-6.

(25) Chen, Z.; Liu, J.; Chen, C.; Huang, Z. Sedimentation of Nanoplastics from Water with Ca/Al Dual Flocculants: Characterization, Interface Reaction, Effects of PH and lon Ratios. Chemosphere 2020, 126450. https://doi.org/10.1016/j.chemosphere.2020.126450.

(26) Della Torre, C.; Bergami, E.; Salvati, A.; Faleri, C.; Cirino, P.; Dawson, K. A.; Corsi, I. Accumulation and Embryotoxicity of Polystyrene Nanoparticles at Early Stage of Development of Sea 

https://doi.org/10.1021/es502569w.

(27) González-Fernández, C.; Toullec, J.; Lambert, C.; Le Goïc, N.; Seoane, M.; Moriceau, B.; Huvet, A.; Berchel, M.; Vincent, D.; Courcot, L.; Soudant, P.; Paul-Pont, I. Do Transparent Exopolymeric Particles (TEP) Affect the Toxicity of Nanoplastics on Chaetoceros Neogracile? Environmental Pollution 2019, 250, 873-882. https://doi.org/10.1016/j.envpol.2019.04.093.

(28) Manfra, L.; Rotini, A.; Bergami, E.; Grassi, G.; Faleri, C.; Corsi, I. Comparative Ecotoxicity of Polystyrene Nanoparticles in Natural Seawater and Reconstituted Seawater Using the Rotifer Brachionus Plicatilis. Ecotoxicology and Environmental Safety 2017, 145, 557-563. https://doi.org/10.1016/j.ecoenv.2017.07.068.

(29) Ramirez, L.; Ramseier Gentile, S.; Zimmermann, S.; Stoll, S. Behavior of TiO2 and CeO2 Nanoparticles and Polystyrene Nanoplastics in Bottled Mineral, Drinking and Lake Geneva Waters. Impact of Water Hardness and Natural Organic Matter on Nanoparticle Surface Properties and Aggregation. Water 2019, 11 (4), 721. https://doi.org/10.3390/w11040721.

(30) Seoane, M.; González-Fernández, C.; Soudant, P.; Huvet, A.; Esperanza, M.; Cid, Á.; Paul-Pont, I. Polystyrene Microbeads Modulate the Energy Metabolism of the Marine Diatom Chaetoceros Neogracile. Environmental Pollution 2019, 251, 363-371. https://doi.org/10.1016/j.envpol.2019.04.142.

(31) Singh, N.; Tiwari, E.; Khandelwal, N.; Darbha, G. K. Understanding the Stability of Nanoplastics in Aqueous Environments: Effect of lonic Strength, Temperature, Dissolved Organic Matter, Clay, and Heavy Metals. Environ. Sci.: Nano 2019, 6 (10), 2968-2976. https://doi.org/10.1039/C9EN00557A.

(32) Song, Z.; Yang, X.; Chen, F.; Zhao, F.; Zhao, Y.; Ruan, L.; Wang, Y.; Yang, Y. Fate and Transport of Nanoplastics in Complex Natural Aquifer Media: Effect of Particle Size and Surface Functionalization. Science of The Total Environment 2019, 669, 120-128. https://doi.org/10.1016/j.scitotenv.2019.03.102.

(33) Tallec, K.; Blard, O.; González-Fernández, C.; Brotons, G.; Berchel, M.; Soudant, P.; Huvet, A.; Paul-Pont, I. Surface Functionalization Determines Behavior of Nanoplastic Solutions in Model Aquatic Environments. Chemosphere 2019, 225, 639-646. https://doi.org/10.1016/j.chemosphere.2019.03.077.

(34) Cai, L.; Hu, L.; Shi, H.; Ye, J.; Zhang, Y.; Kim, H. Effects of Inorganic lons and Natural Organic Matter on the Aggregation of Nanoplastics. Chemosphere 2018, 197, 142-151. https://doi.org/10.1016/j.chemosphere.2018.01.052.

(35) Dong, Z.; Zhang, W.; Qiu, Y.; Yang, Z.; Wang, J.; Zhang, Y. Cotransport of Nanoplastics (NPs) with Fullerene (C60) in Saturated Sand: Effect of NPs/C60 Ratio and Seawater Salinity. Water Research 2019, 148, 469-478. https://doi.org/10.1016/j.watres.2018.10.071.

(36) Magrì, D.; Sánchez-Moreno, P.; Caputo, G.; Gatto, F.; Veronesi, M.; Bardi, G.; Catelani, T.; Guarnieri, D.; Athanassiou, A.; Pompa, P. P.; Fragouli, D. Laser Ablation as a Versatile Tool To Mimic Polyethylene Terephthalate Nanoplastic Pollutants: Characterization and Toxicology Assessment. ACS Nano 2018, 12 (8), 7690-7700. https://doi.org/10.1021/acsnano.8b01331. 
(38) Wu, J.; Jiang, R.; Lin, W.; Ouyang, G. Effect of Salinity and Humic Acid on the Aggregation and Toxicity of Polystyrene Nanoplastics with Different Functional Groups and Charges. Environmental Pollution 2019, 245, 836-843. https://doi.org/10.1016/j.envpol.2018.11.055.

(39) Yu, S.; Shen, M.; Li, S.; Fu, Y.; Zhang, D.; Liu, H.; Liu, J. Aggregation Kinetics of Different Surface-Modified Polystyrene Nanoparticles in Monovalent and Divalent Electrolytes. Environmental Pollution 2019, 255, 113302. https://doi.org/10.1016/j.envpol.2019.113302.

(40) Zhang, F.; Wang, Z.; Wang, S.; Fang, H.; Wang, D. Aquatic Behavior and Toxicity of Polystyrene Nanoplastic Particles with Different Functional Groups: Complex Roles of PH, Dissolved Organic Carbon and Divalent Cations. Chemosphere 2019, 228, 195-203. https://doi.org/10.1016/j.chemosphere.2019.04.115.

(41) Saavedra, J.; Stoll, S.; Slaveykova, V. I. Influence of Nanoplastic Surface Charge on Eco-Corona Formation, Aggregation and Toxicity to Freshwater Zooplankton. Environmental Pollution 2019, 252, 715-722. https://doi.org/10.1016/j.envpol.2019.05.135.

(42) Summers, S.; Henry, T.; Gutierrez, T. Agglomeration of Nano- and Microplastic Particles in Seawater by Autochthonous and de Novo-Produced Sources of Exopolymeric Substances. Marine Pollution Bulletin 2018, 130, 258-267. https://doi.org/10.1016/j.marpolbul.2018.03.039.

(43) Dong, S.; Cai, W.; Xia, J.; Sheng, L.; Wang, W.; Liu, H. Aggregation Kinetics of Fragmental PET Nanoplastics in Aqueous Environment: Complex Roles of Electrolytes, PH and Humic Acid. Environmental Pollution 2020, 115828. https://doi.org/10.1016/j.envpol.2020.115828.

(44) Liu, Y.; Hu, Y.; Yang, C.; Chen, C.; Huang, W.; Dang, Z. Aggregation Kinetics of UV Irradiated Nanoplastics in Aquatic Environments. Water Research 2019, 163, 114870. https://doi.org/10.1016/j.watres.2019.114870.

(45) Okshevsky, M.; Gautier, E.; Farner, J. M.; Schreiber, L.; Tufenkji, N. Biofilm Formation by Marine Bacteria Is Impacted by Concentration and Surface Functionalization of Polystyrene Nanoparticles in a Species-specific Manner. Environmental Microbiology Reports 2020, 12 (2), 203213. https://doi.org/10.1111/1758-2229.12824.

(46) Flemming, H.-C.; Wingender, J. The Biofilm Matrix. Nat Rev Microbiol 2010, 8 (9), 623-633. https://doi.org/10.1038/nrmicro2415.

(47) Stumm, W.; Morgan, J. J. Aquatic Chemistry: Chemical Equilibria and Rates in Natural Waters; Wiley: New York, 1996.

(48) El Hadri, H.; Gigault, J.; Maxit, B.; Grassl, B.; Reynaud, S. Nanoplastic from Mechanically Degraded Primary and Secondary Microplastics for Environmental Assessments. Nanolmpact 2020, 100206. https://doi.org/10.1016/j.impact.2019.100206.

(49) Holthoff, H.; Egelhaaf, S. U.; Borkovec, M.; Schurtenberger, P.; Sticher, H. Coagulation Rate Measurements of Colloidal Particles by Simultaneous Static and Dynamic Light Scattering. Langmuir 1996, 12 (23), 5541-5549. https://doi.org/10.1021/la960326e.

(50) Gigault, J.; El Hadri, H.; Reynaud, S.; Deniau, E.; Grassl, B. Asymmetrical Flow Field Flow Fractionation Methods to Characterize Submicron Particles: Application to Carbon-Based Aggregates and Nanoplastics. Analytical and Bioanalytical Chemistry 2017, 409 (29), 6761-6769. https://doi.org/10.1007/s00216-017-0629-7. 
(51) Gregory, J. Approximate Expressions for Retarded van Der Waals Interaction. Journal of Colloid and Interface Science 1981, 83 (1), 138-145. https://doi.org/10.1016/0021-9797(81)90018-7.

(52) Particle Deposition and Aggregation: Measurement, Modelling and Simulation; Elimelech, M., Ed.; Colloid and surface engineering series; Butterworth-Heinemann: Oxford, 1998.

(53) Hogg, R.; Healy, T. W.; Fuerstenau, D. W. Mutual Coagulation of Colloidal Dispersions. Trans. Faraday Soc. 1966, 62, 1638. https://doi.org/10.1039/tf9666201638.

(54) van Oss, C. J. Acid-Base Interfacial Interactions in Aqueous Media. Colloids and Surfaces A: Physicochemical and Engineering Aspects 1993, 78, 1-49. https://doi.org/10.1016/09277757(93)80308-2.

(55) Valsesia, A.; Desmet, C.; Ojea-Jiménez, I.; Oddo, A.; Capomaccio, R.; Rossi, F.; Colpo, P. Direct Quantification of Nanoparticle Surface Hydrophobicity. Commun Chem 2018, 1 (1), 53. https://doi.org/10.1038/s42004-018-0054-7.

(56) Vold, M. J. Van Der Waals' Attraction between Anisometric Particles. Journal of Colloid Science 1954, 9 (5), 451-459. https://doi.org/10.1016/0095-8522(54)90032-X.

(57) Baalousha, M. Effect of Nanomaterial and Media Physicochemical Properties on Nanomaterial Aggregation Kinetics. Nanolmpact 2017, 6, 55-68. https://doi.org/10.1016/j.impact.2016.10.005.

(58) Zhou, D.; Keller, A. A. Role of Morphology in the Aggregation Kinetics of ZnO Nanoparticles. Water Research 2010, 44 (9), 2948-2956. https://doi.org/10.1016/j.watres.2010.02.025.

(59) Wu, W.; Giese, R. F.; van Oss, C. J. Stability versus Flocculation of Particle Suspensions in Water-Correlation with the Extended DLVO Approach for Aqueous Systems, Compared with Classical DLVO Theory. Colloids and Surfaces B: Biointerfaces 1999, 14 (1-4), 47-55. https://doi.org/10.1016/S0927-7765(99)00023-5.

(60) Lan, Y.; Caciagli, A.; Guidetti, G.; Yu, Z.; Liu, J.; Johansen, V. E.; Kamp, M.; Abell, C.; Vignolini, S.; Scherman, O. A.; Eiser, E. Unexpected Stability of Aqueous Dispersions of Raspberry-like Colloids. Nat Commun 2018, 9 (1), 3614. https://doi.org/10.1038/s41467-018-05560-3.

(61) DelRio, F. W.; de Boer, M. P.; Knapp, J. A.; David Reedy, E.; Clews, P. J.; Dunn, M. L. The Role of van Der Waals Forces in Adhesion of Micromachined Surfaces. Nature Materials 2005, 4 (8), 629634. https://doi.org/10.1038/nmat1431.

(62) Huang, X.; Bhattacharjee, S.; Hoek, E. M. V. Is Surface Roughness a "Scapegoat" or a Primary Factor When Defining Particle-Substrate Interactions? Langmuir 2010, 26 (4), 2528-2537. https://doi.org/10.1021/la9028113.

(63) Petosa, A. R.; Jaisi, D. P.; Quevedo, I. R.; Elimelech, M.; Tufenkji, N. Aggregation and Deposition of Engineered Nanomaterials in Aquatic Environments: Role of Physicochemical Interactions. Environmental Science \& Technology 2010, 44 (17), 6532-6549. https://doi.org/10.1021/es100598h.

(64) Goodwin, J. W. Colloids and Interfaces with Surfactants and Polymers: An Introduction, Wiley.; 2004.

(65) Messaud, F. A.; Sanderson, R. D.; Runyon, J. R.; Otte, T.; Pasch, H.; Williams, S. K. R. An Overview on Field-Flow Fractionation Techniques and Their Applications in the Separation and 
(66) Beckett, Ronald.; Jue, Zhang.; Giddings, J. Calvin. Determination of Molecular Weight Distributions of Fulvic and Humic Acids Using Flow Field-Flow Fractionation. Environ. Sci. Technol. 1987, 21 (3), 289-295. https://doi.org/10.1021/es00157a010.

(67) Yu, S.; Liu, J.; Yin, Y.; Shen, M. Interactions between Engineered Nanoparticles and Dissolved Organic Matter: A Review on Mechanisms and Environmental Effects. Journal of Environmental Sciences 2018, 63, 198-217. https://doi.org/10.1016/j.jes.2017.06.021.

(68) Chen, C.-S.; Le, C.; Chiu, M.-H.; Chin, W.-C. The Impact of Nanoplastics on Marine Dissolved Organic Matter Assembly. Science of The Total Environment 2018, 634, 316-320. https://doi.org/10.1016/j.scitotenv.2018.03.269.

(69) He, L.; Rong, H.; Wu, D.; Li, M.; Wang, C.; Tong, M. Influence of Biofilm on the Transport and Deposition Behaviors of Nano- and Micro-Plastic Particles in Quartz Sand. Water Research 2020, 115808. https://doi.org/10.1016/j.watres.2020.115808.

(70) Bhattacharya, P.; Lin, S.; Turner, J. P.; Ke, P. C. Physical Adsorption of Charged Plastic Nanoparticles Affects Algal Photosynthesis. The Journal of Physical Chemistry C 2010, 114 (39), 16556-16561. https://doi.org/10.1021/jp1054759.

(71) Xu, R. Particle Characterization: Light Scattering Methods; Springer Netherlands, 2006.

(72) Lodeiro, P.; Achterberg, E. P.; Pampín, J.; Affatati, A.; El-Shahawi, M. S. Silver Nanoparticles Coated with Natural Polysaccharides as Models to Study AgNP Aggregation Kinetics Using UV-Visible Spectrophotometry upon Discharge in Complex Environments. Science of The Total Environment 2016, 539, 7-16. https://doi.org/10.1016/j.scitotenv.2015.08.115.

(73) Saleh, N. B.; Pfefferle, L. D.; Elimelech, M. Influence of Biomacromolecules and Humic Acid on the Aggregation Kinetics of Single-Walled Carbon Nanotubes. Environ. Sci. Technol. 2010, 44 (7), 2412-2418. https://doi.org/10.1021/es903059t.

(74) Espinasse, B.; Hotze, E. M.; Wiesner, M. R. Transport and Retention of Colloidal Aggregates of $\mathrm{C}_{60}$ in Porous Media: Effects of Organic Macromolecules, Ionic Composition, and Preparation Method. Environ. Sci. Technol. 2007, 41 (21), 7396-7402. https://doi.org/10.1021/es0708767.

(75) Hyung, H.; Kim, J.-H. Natural Organic Matter (NOM) Adsorption to Multi-Walled Carbon Nanotubes: Effect of NOM Characteristics and Water Quality Parameters. Environmental Science \& Technology 6. https://doi.org/10.1021/es702916h.

(76) Loosli, F.; Vitorazi, L.; Berret, J.-F.; Stoll, S. Towards a Better Understanding on Agglomeration Mechanisms and Thermodynamic Properties of TiO2 Nanoparticles Interacting with Natural Organic Matter. Water Research 2015, 80, 139-148. https://doi.org/10.1016/j.watres.2015.05.009.

(77) Chen, K. L.; Mylon, S. E.; Elimelech, M. Aggregation Kinetics of Alginate-Coated Hematite Nanoparticles in Monovalent and Divalent Electrolytes. Environ. Sci. Technol. 2006, 40 (5), 15161523. https://doi.org/10.1021/es0518068.

(78) Cunha, C.; Silva, L.; Paulo, J.; Faria, M.; Nogueira, N.; Cordeiro, N. Microalgal-Based Biopolymer for Nano- and Microplastic Removal: A Possible Biosolution for Wastewater Treatment. Environmental Pollution 2020, 263, 114385. https://doi.org/10.1016/j.envpol.2020.114385. 
(79) Liu, J.; Ma, Y.; Zhu, D.; Xia, T.; Qi, Y.; Yao, Y.; Guo, X.; Ji, R.; Chen, W. Polystyrene NanoplasticsEnhanced Contaminant Transport: Role of Irreversible Adsorption in Glassy Polymeric Domain.

689 https://doi.org/10.1021/acs.est.7b05211.

690 (80) Velzeboer, I.; Kwadijk, C. J. A. F.; Koelmans, A. A. Strong Sorption of PCBs to Nanoplastics, 691 Microplastics, Carbon Nanotubes, and Fullerenes. Environ. Sci. Technol. 2014, 48 (9), 4869-4876.

692 https://doi.org/10.1021/es405721v.

693 (81) Lin, W.; Jiang, R.; Xiao, X.; Wu, J.; Wei, S.; Liu, Y.; Muir, D. C. G.; Ouyang, G. Joint Effect of 694 Nanoplastics and Humic Acid on the Uptake of PAHs for Daphnia Magna: A Model Study. Journal of 695 Hazardous Materials 2020, 391, 122195. https://doi.org/10.1016/j.jhazmat.2020.122195.

696 


\title{
Supporting Information for:
}

\section{Stabilization of fragmental polystyrene nanoplastic by natural organic matter:}

\section{Insight into mechanisms}

\author{
Alice Pradel ${ }^{\mathrm{a}}$, Séléna Ferreres ${ }^{\mathrm{a}}$, Cloé Veclin ${ }^{\mathrm{b}}$, Hind El Hadri ${ }^{\mathrm{b}}$, Maud Gautier ${ }^{\mathrm{a}}$, Bruno Grassl ${ }^{\mathrm{b}}, \mathrm{Julien}$ \\ Gigault ${ }^{\mathrm{a}, \mathrm{c}^{*}}$ \\ ${ }^{a}$ Univ Rennes, CNRS, Géosciences Rennes - UMR 6118, 35000 Rennes, France \\ ${ }^{b}$ CNRS/ Univ Pau \& Pays Adour/ E2S UPPA, Institut des sciences analytiques et de physicochimie pour \\ l'environnement et les matériaux, UMR 5254, 64000, Pau, France \\ ${ }^{c}$ TAKUVIK laboratory, CNRS/Université Laval, 1045, av. de la Médecine, Québec (Québec) G1V OA6 \\ Canada
}

*alice.pradel@univ-rennesl.fr; * julien.gigault@takuvik.ulaval.ca

\section{The Supporting Information contains 9 figures, 1 table, 2 sections of text (SI1 and SI2), 9 references, 13 pages.}

\section{Table of contents:}

Figure S1: Transmission Electron Microscopy Images of a) NPT-P and b) PSL COOH

Figure S2: Histogram of short axis (green) and long axis (purple), as determined by TEM images of a) PSL COOH and b) NPT-P nanoplastic models in linear distribution (PSL COOH: $n=212$ and NPT$\mathrm{P}: \mathrm{n}=283$ )

Supplemental Information 1: Method for Asymmetrical Flow Field Flow Fractionation (A4F) coupled to Static Light Scattering (SLS)

Figure S4: Determination of the Critical Coagulation Concentration (CCC) of NPT-P particles in NaCl at a) $\mathrm{pH} 6.5$ and b) $\mathrm{pH} 8$

Supplemental Information 2: Extended Derjaguin Landau Verwey Overbeek (XDLVO) theory of colloidal stability

Table S1: Energy barrier between particles according to DLVO and XDLVO theories, scaled to $\mathrm{k}_{\mathrm{B}} \mathrm{T}$

Figure S5: Interaction energy, scaled to kBT, between different nanoplastic models, according to XDLVO theory

Figure S6: Molar mass distribution of sodium alginate, as determined by SEC coupled to SLS and RI

Figure S7: Transmission Electron Microscopy Images of a) b) NPT-P without organic matter c) d) NPT-P with humic acid (HA) and e) f) NPT-P with sodium alginate (SA)

Figure S8: Relative particle concentration of NPT-P at 5 and $600 \mathrm{mmol} \mathrm{L}^{-1} \mathrm{NaCl}$ at a) $\mathrm{pH} 6.5, \mathrm{~b}$ ) $\mathrm{pH} 8$, c) with $30 \mathrm{mg} \mathrm{L}^{-1}$ humic acid (HA) at pH 6.5 and d) with $57 \mathrm{mg} \mathrm{L}^{-1}$ sodium alginate (SA) at $\mathrm{pH} 8$.

Figure S9: Aggregation rate of NPT-P with a) $30 \mathrm{mg} \mathrm{L}^{-1}$ humic acid b) $57 \mathrm{mg} \mathrm{L}^{-1}$ sodium alginate, as a function of ionic strength and $\mathrm{pH}$ (Error bars $=$ standard deviation) 


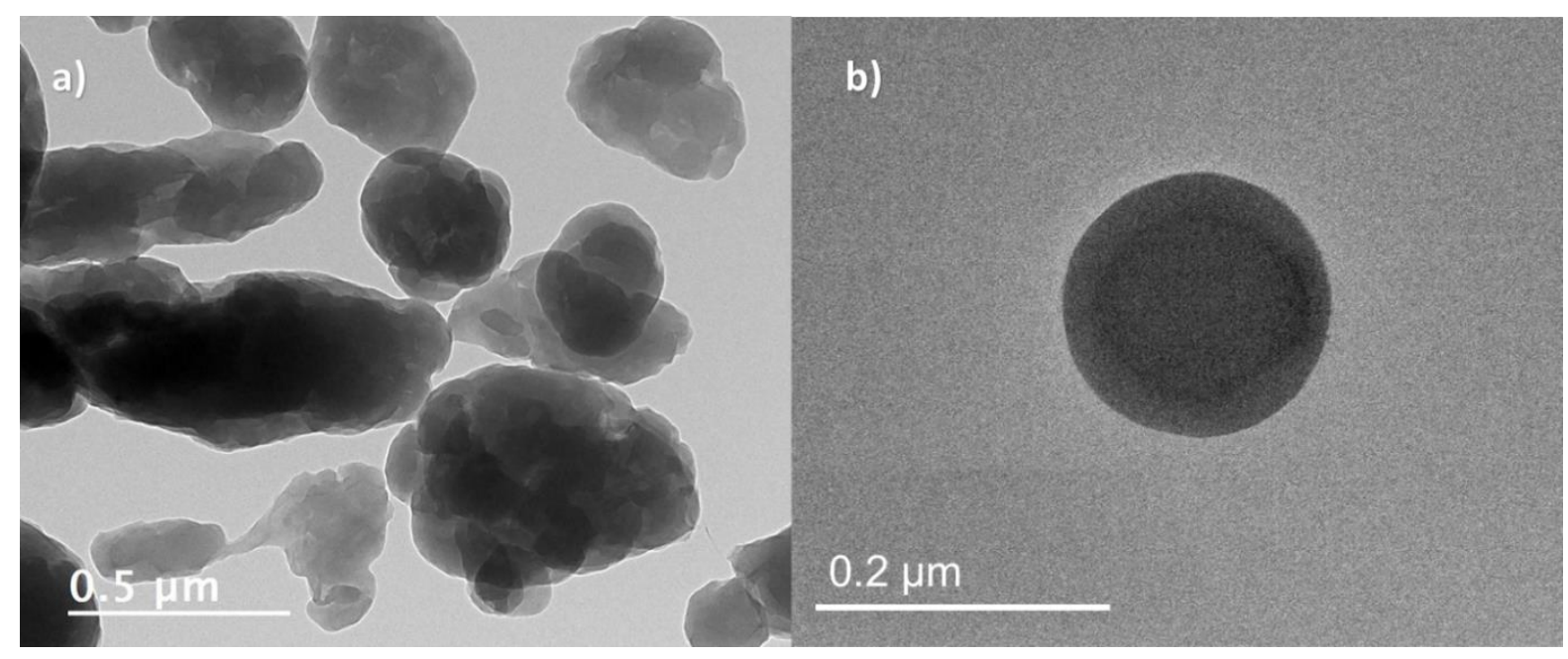

Figure S1: Transmission Electron Microscopy Images of a) NPT-P and b) PSL COOH 

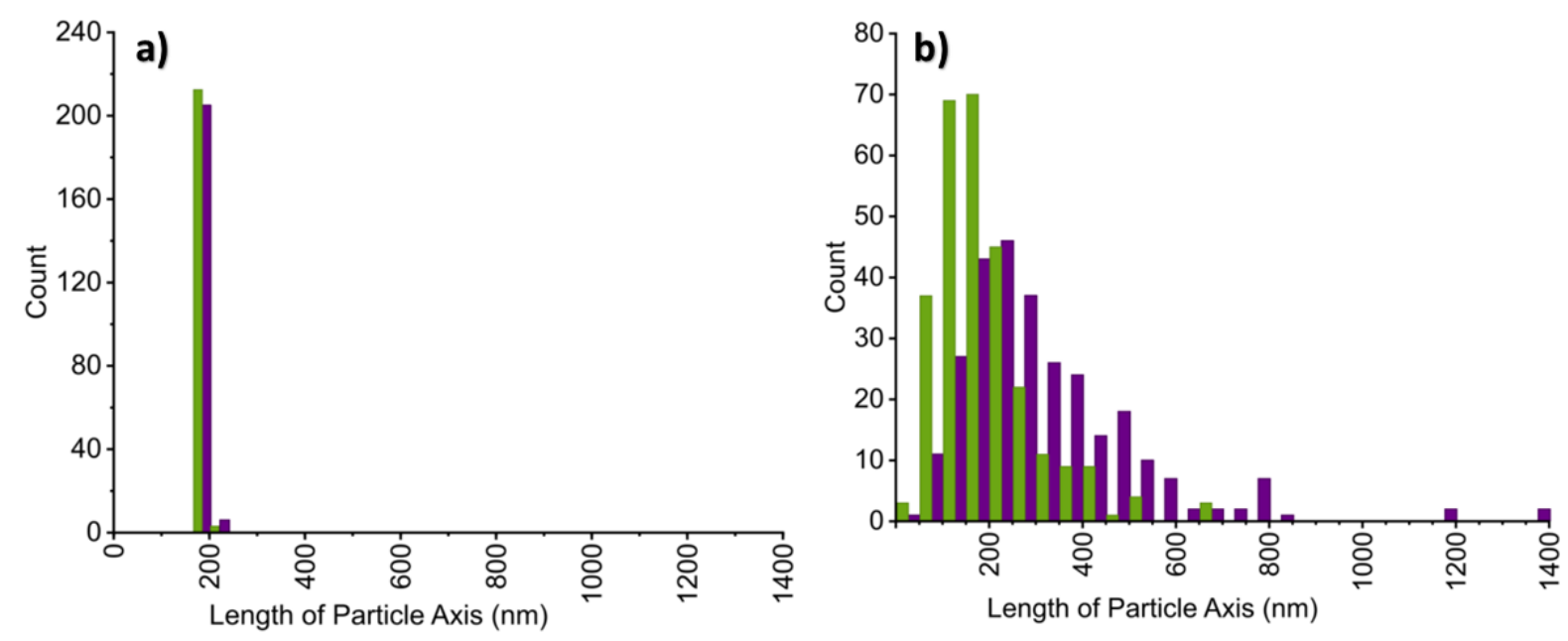

Figure S2: Histogram of short axis (green) and long axis (purple), as determined by TEM images of a) PSL COOH and b) NPT-P nanoplastic models in linear distribution (PSL COOH: $n=212$ and NPT-P: $n=283$ )

TEM images were obtained by a Jeol JEM $2100 \mathrm{HR}(200 \mathrm{kV})$ with an $\mathrm{LaB}_{6}$ filament. The camera was a Gatan Orius SC 200 D. A $4 \mu \mathrm{L}$ drop was deposited on a full carbon grid and allowed to air dry. Data was analyzed with ImageJ software and the NanoDefine plugin, using the watershed fitting mode (Verleysen et al., 2019). The length of the major axi and minor axi were the longest and shortest lengths of the minimum bounding rectangle. Based on these images and assuming the NPT-P particles is either a sphere or an ellipsoid, the specific surface area was determined to be $30.2 \pm 16.4$ and $34.2 \pm 18.9$ $\mathrm{m}^{2} \mathrm{~g}^{-1}$, respectively. The specific surface area was determined to be $29.6 \pm 0.6 \mathrm{~m}^{2} \mathrm{~g}^{-1}$ for PSL COOH.

The NPT-P minor and major axi followed a log-normal distribution, as determined with the orthogonal distance regression method. Equation (S1) was used to fit the data, with $\mu$ the average of distribution and $\sigma$ the standard deviation of distribution.

$$
y=\frac{A}{\sigma x \sqrt{2 \pi}} \exp ^{\frac{-\ln \left(\frac{x}{\mu}\right)^{2}}{2 \sigma^{2}}}
$$

The following parameters were determined:

- For the NPT-P major axis:

$$
\begin{array}{ll}
\circ & \mu=395.70 \pm 30.65 \\
\circ & \sigma=380.52 \pm 48.34 \\
\circ & \mathrm{A}=20734.02 \pm 6774.76 \\
\circ & \mathrm{R}^{2}(\mathrm{COD})=0.99994
\end{array}
$$

- For the NPT-P minor axis :
○ $\mu=213.54 \pm 3.93$
○ $\sigma=461.88 \pm 13.53$
○ $\mathrm{A}=9986.26 \pm 260.98$
○ $\mathrm{R}^{2}(\mathrm{COD})=0.98101$ 


\section{Supplemental Information 1:}

Method for Asymmetrical Flow Field Flow Fractionation (A4F) coupled to Static Light Scattering (SLS)

The mobile phase flow was generated by a 1200 series high-performance liquid chromatography (HPLC) pump (Agilent Technologies, Les Ulis, France). The Asymmetrical Flow Field Flow Fractionation (A4F) system was an Eclipse 3+ (Wyatt Technology, Dernbach, Germany). Injections were performed with an Agilent Technologies 1200 series autosampler. At the outlet, the detectors were a 1200 series UV-vis absorbance detector (Agilent Technologies, Les Ulis, France) and a DAWN HELEOS multi-angle laser, static light scattering (SLS) detector (Wyatt Technology). For UV-Vis detection, the selected wavelength was $254 \mathrm{~nm}$.

The A4F channel height was established using a spacer (Mylar film) of $250 \mu \mathrm{m}$. The dimensions of the spacer were $26.5 \mathrm{~cm}$ length and narrowing width from 2.1 to $0.6 \mathrm{~cm}$. The accumulation wall was composed of Polyethersulfone (PES) $10 \mathrm{kDa}$ membranes (Wyatt Technology). The A4F method was based on the general (fast) method O described by Gigault et al. (2017). The elution flow rate was fixed at $0.5 \mathrm{~mL} \mathrm{~min}^{-1}$. The injection flow rate was fixed at $0.2 \mathrm{~mL} \mathrm{~min}^{-1}$. The focus-flow during the relaxation was $0.5 \mathrm{~mL} \cdot \mathrm{min}^{-1}$ and the cross-flow rate during elution $\left(\mathrm{V}_{\mathrm{c}}\right)$, was a function of time $(\mathrm{t}) \mathrm{Vc}=2 \mathrm{e}^{-0.27 \mathrm{t}}$.

The mobile phase was composed of $0.5 \mathrm{mmol} \mathrm{L}^{-1} \mathrm{NaNO} 3$ (>99\% purity Reagent Plus, Sigma Aldrich), which was filtered on polyethersulfone (PES) filters $(0.1 \mu \mathrm{m}$, Pall®), purchased from VWR (Fontenay-sous-Bois, France). The injection volume was $100 \mu \mathrm{L}$. First, the effects of the duration of the focus period and the ionic strength of the injected dispersion, on the quality of detection were studied. Subsequently, a focus time of 5 minutes and an ionic strength of $600 \mathrm{mmol} \mathrm{L}^{-1}$ was selected. The injected dispersion was prepared in the same way as for the aggregation kinetic study, described below.

Data from a minimum of 14 out of 18 SLS detectors were collected and processed using Astra software, version 6 (Wyatt Technology). The radius of gyration ( $\mathrm{Rg}$ ) was determined using the Berry formalism using SLS signal at different angles. 

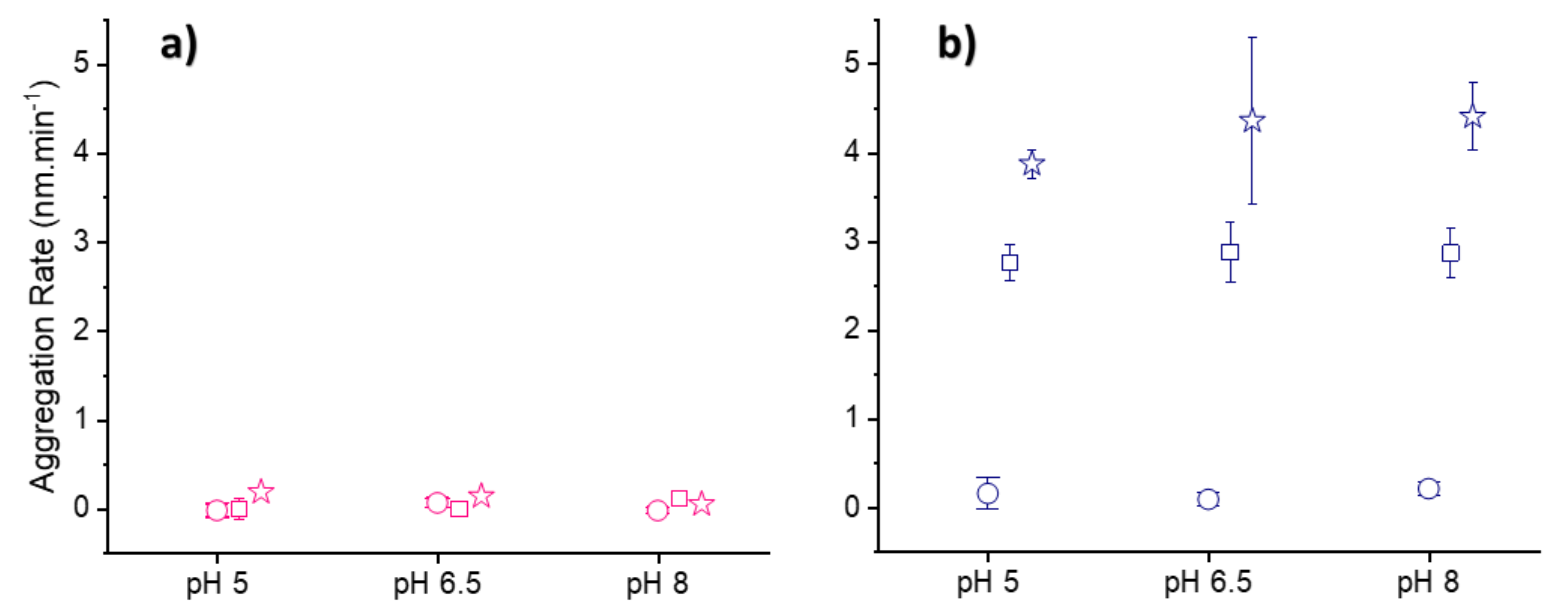

$5 \mathrm{mmol} \mathrm{L}^{-1} \square 50 \mathrm{mmol} \mathrm{L}^{-1}$ ¿̧ $600 \mathrm{mmol} \mathrm{L}^{-1}$

Figure S3: Aggregation rate of a) PSL COOH and b) NPT-P models, as a function of NaCl concentration and pH (Error bars $=$ standard deviation $)$ 

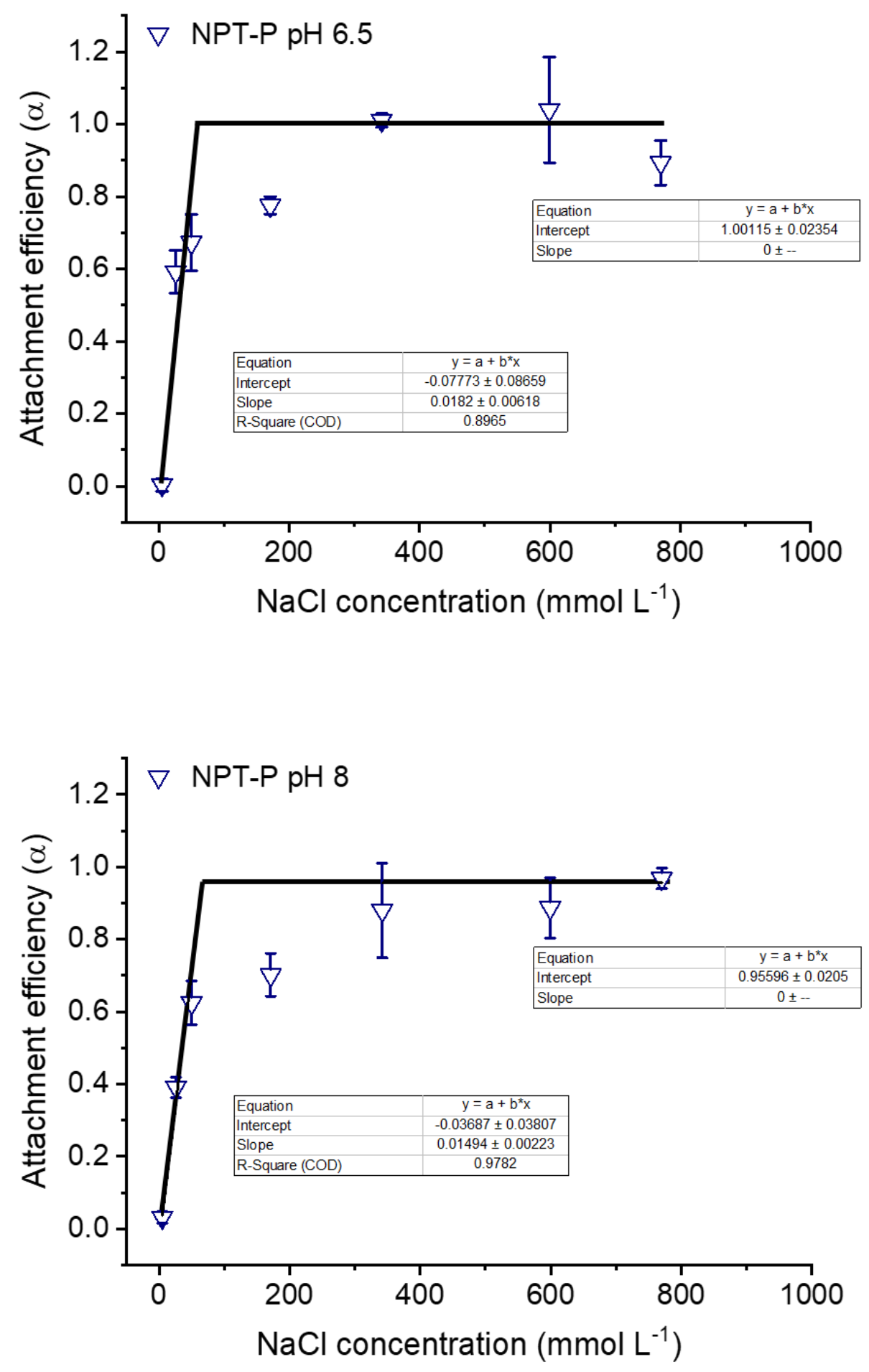

Figure S4: Determination of the Critical Coagulation Concentration (CCC) of NPT-P particles in NaCl at $\mathrm{pH} 6.5$ and $\mathrm{pH} 8$ 
Table S1: Energy barrier between particles according to DLVO and XDLVO theories, scaled to $k_{B} T$

\begin{tabular}{|c|c|c|c|c|}
\hline Particle 1 & PSL COOH & \multicolumn{3}{|c|}{ NPT-P } \\
\hline Particle 2 & PSL COOH & NPT-P & $\begin{array}{c}\text { small (50 nm) } \\
\text { NPT-P asperity* }\end{array}$ & $\begin{array}{c}\text { large (100 nm) } \\
\text { NPT-P asperity }\end{array}$ \\
\hline DLVO theory & 70 & 76 & 21 & 38 \\
\hline XDLVO theory & 28 & 24 & 7 & 12 \\
\hline
\end{tabular}

${ }^{*}$ Assuming the NPT-P particles are ellipsoids, the smallest radius of curvature, defined as the square of the short axis divided by the long axis, is on average $64 \mathrm{~nm}$.

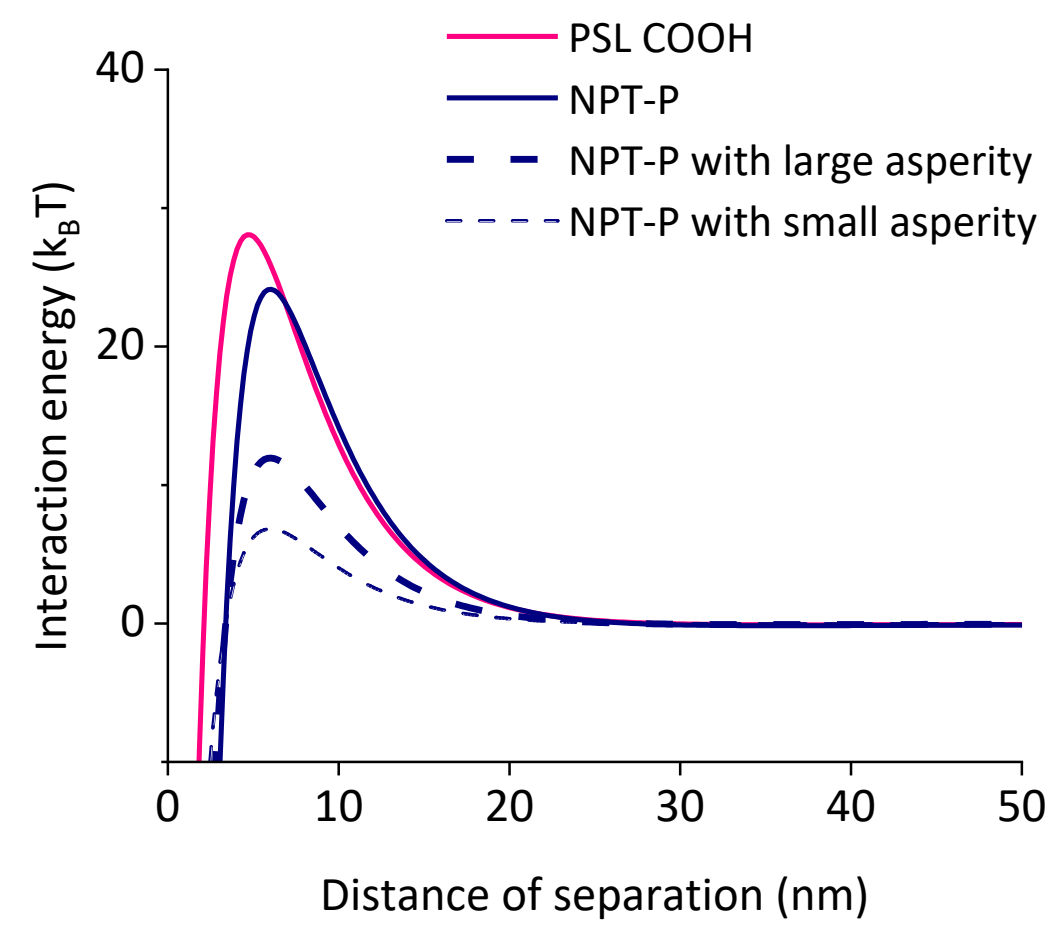

Figure S5: Interaction energy, scaled to $k_{B} T$, between different nanoplastic models, according to XDLVO theory 


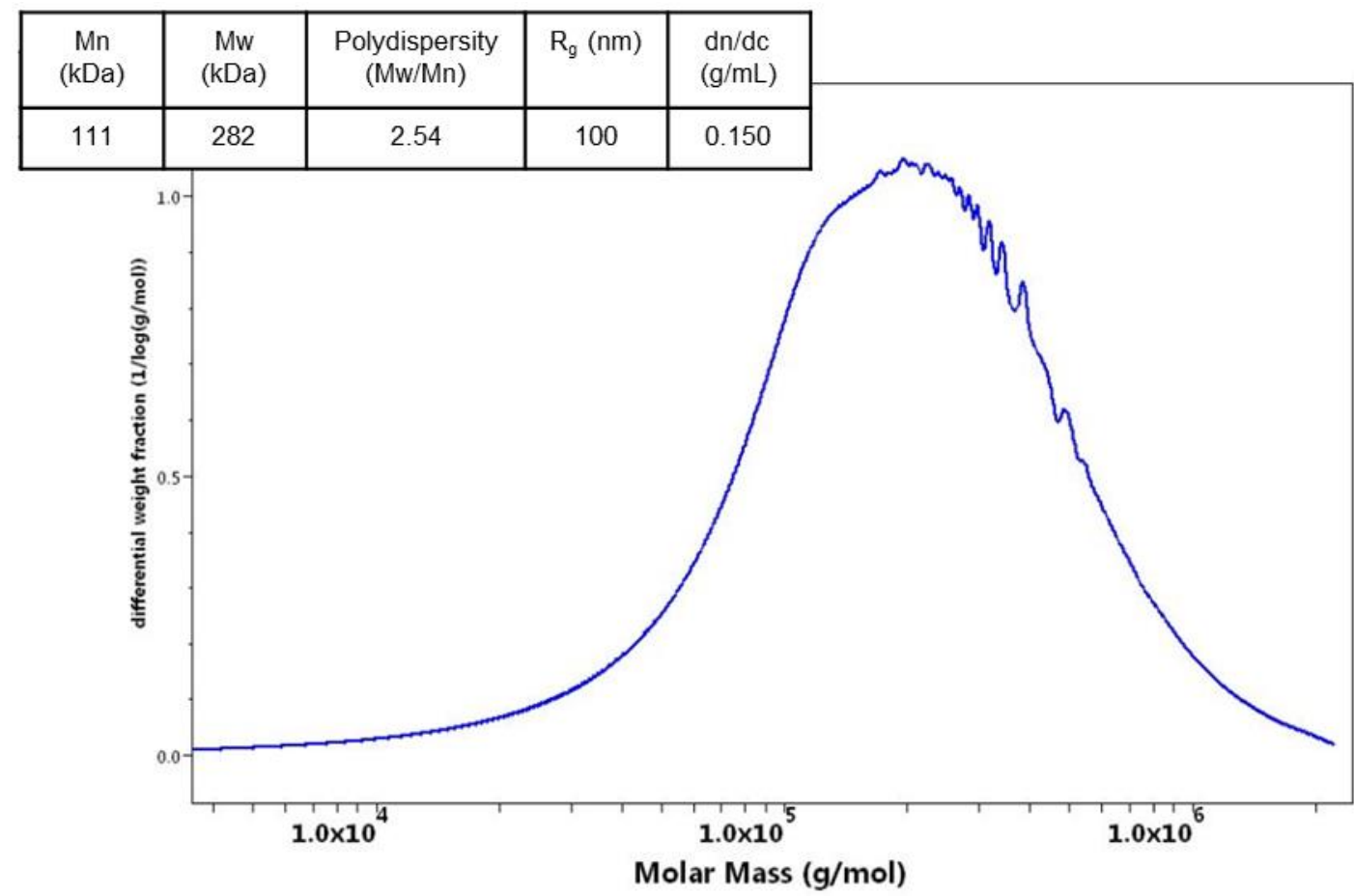

Figure S6: Molar mass distribution of sodium alginate, as determined by SEC coupled to SLS and RI

The source and extraction method of sodium alginate are not standardized, which results in wide variations in molar mass (Masuelli and Illanes, 2014). So, the weight-averaged molar mass of this macromolecule was measured by SEC coupled to SLS and refractive index (RI) measurement. On-line purified mobile phase $\left(0.1 \mathrm{mmol} \mathrm{L}^{-1} \mathrm{NaNO}_{3}\right)$ was delivered with an 1200 series HPLC pump (Agilent Technologies) at a flow rate of $5 \mathrm{~mL} \mathrm{~min}^{-1}$ to a chromatographic pre-column SB-807G, followed by four columns, SB-805HQ, SB-807HQ, SB-802HQ and SB-803HQ (Shodex, Munich, Germany). The temperature was kept at $30^{\circ} \mathrm{C}$. Sodium alginate was injected at a concentration of $500 \mathrm{mg} \mathrm{L}^{-1}$ in $600 \mathrm{mmol} \mathrm{L}^{-1} \mathrm{NaCl}$. At the outlet, sodium alginate was characterized by the DAWN HELEOS SLS detector (Wyatt Technology) and RI was measured by an Optilab T-rEX (Wyatt Technology). 


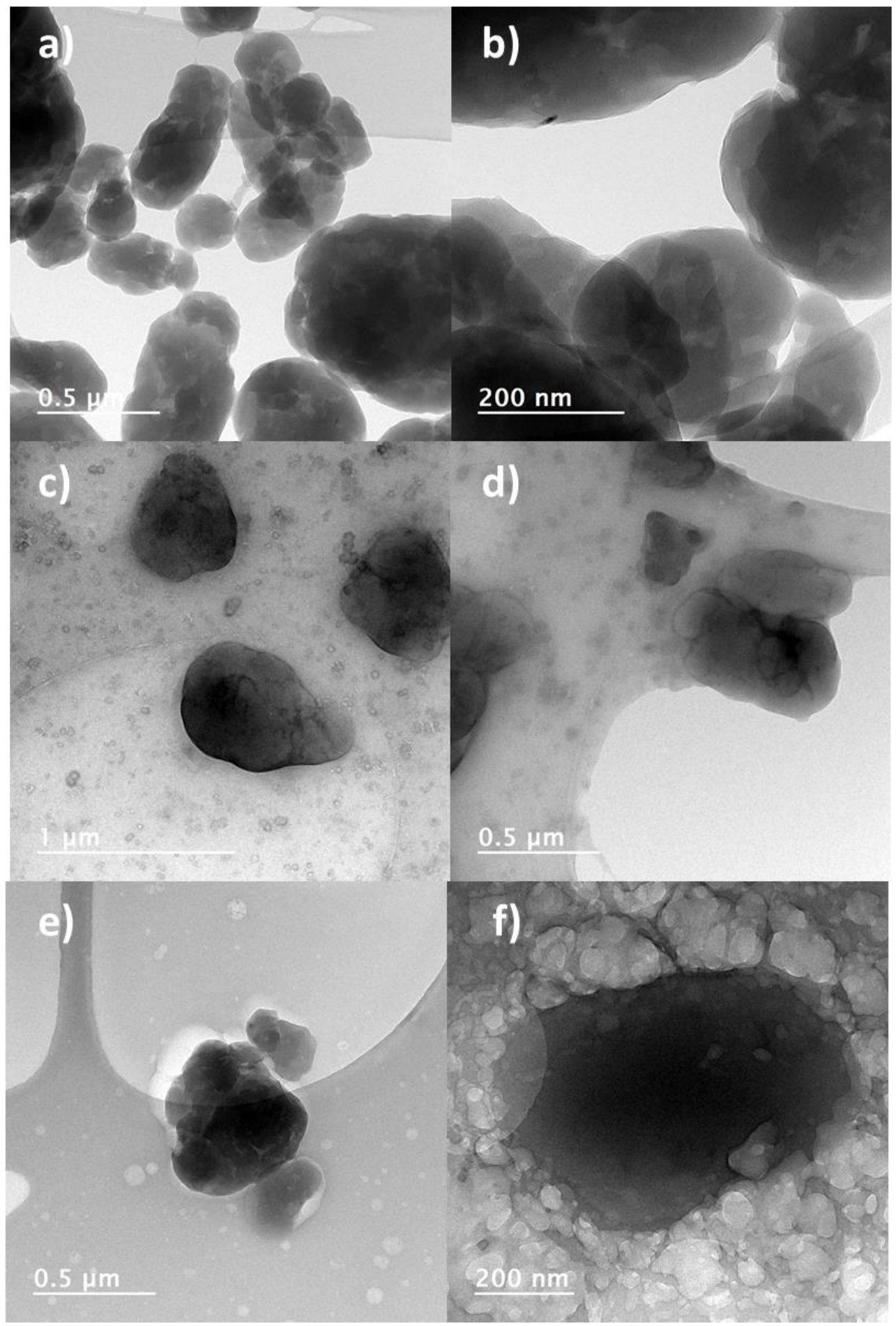

Figure S7: Transmission Electron Microscopy Images of a) b) NPT-P without organic matter c) d) NPT-P with humic acid (HA) and e) f) NPT-P with sodium alginate (SA)

Images a, c and e, show NPT-P at a lower magnification, to illustrate the matrix of NOM (c and e) or lack thereof. Images $b, d$, and $f$ were taken at a higher magnification to observe the interface between NOM and NPT-P. The particles appear to be embedded in SA (e and f). In image e, the lighter halo around the particle is probably caused by the displacement of the. Figures $\mathrm{c}$ and $\mathrm{d}$ show that while NPT-P is also embedded in HA (c), at closer magnification, they seem less closely associated (d). 

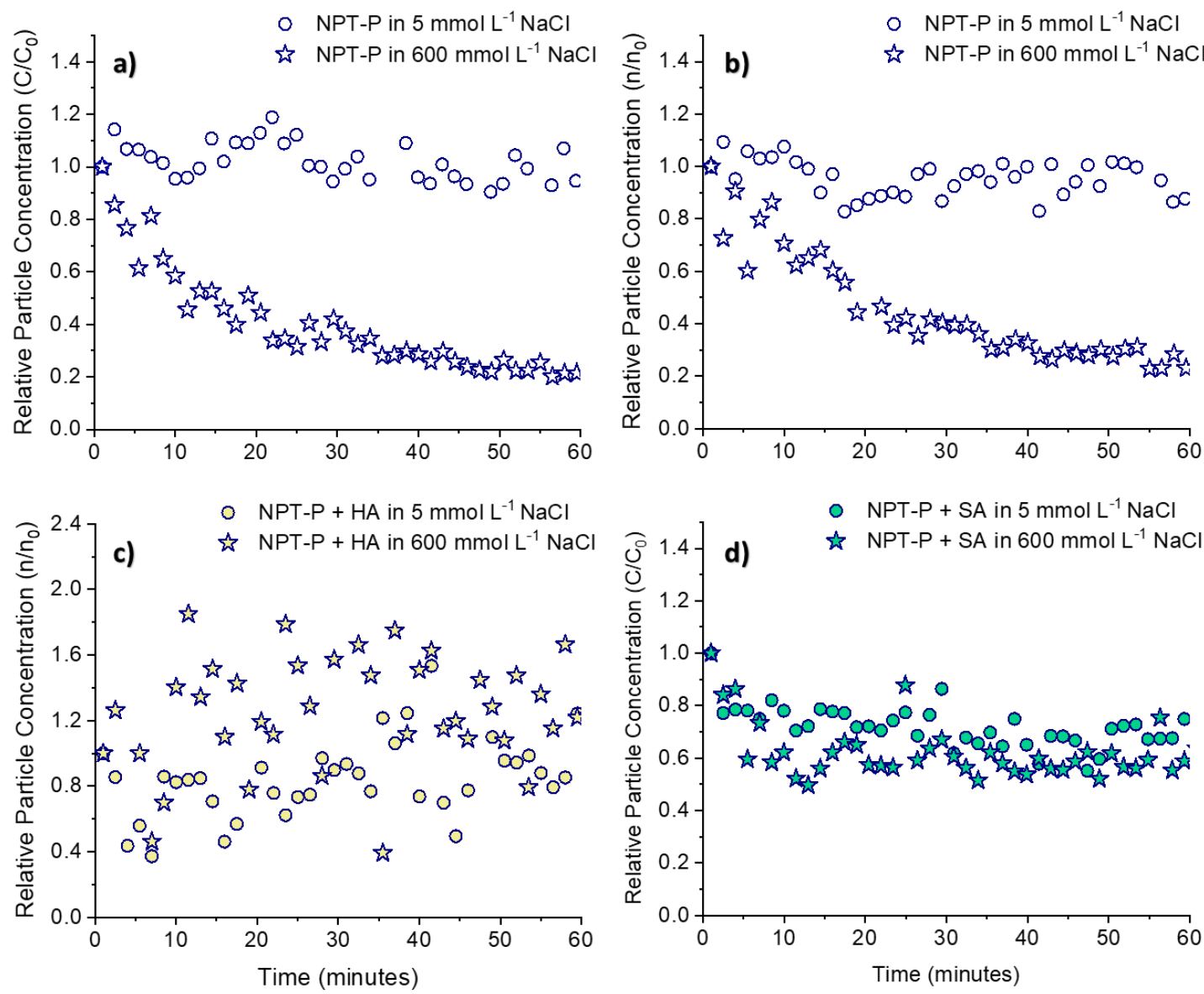

Figure S8: Relative particle concentration of NPT-P at 5 and $600 \mathrm{mmol} \mathrm{L}^{-1} \mathrm{NaCl}$ at a) pH 6.5, b) pH 8, c) with $30 \mathrm{mg} \mathrm{L}^{-1}$ humic acid (HA) at $\mathrm{pH} 6.5$ and d) with $50 \mathrm{mg} \mathrm{L}^{-1}$ sodium alginate (SA) at $\mathrm{pH} 8$

The relative particle concentration $\left(\mathrm{n} / \mathrm{n}_{0}\right)$ was determined according to the relation that links the intensity of scattered light and the particle size. This relationship is only valid assuming that all particles are spherical (Wyatt, 1993). The intensity of scattered light, at a give scattering angle and particle concentration $\mathrm{I}_{(\Theta, \mathrm{c})}$, is given by the following equation:

$$
I_{(\theta, c)}=K_{c} M_{W} P_{(\theta)}
$$

with $\Theta$, the angle at which light is scattered, which is equal to 170 degrees and $\mathrm{c}$ the concentration in $\mathrm{g} \mathrm{L}^{-1}, \mathrm{~K}$ the instrument constant, $\mathrm{M}_{\mathrm{w}}$ the molar mass in $\mathrm{g} \mathrm{mol}^{-1}$ and $\mathrm{P}_{\Theta}$ the form factor. For a sphere, the form factor $\mathrm{P}_{\ominus}$ is given by:

$$
P_{(\theta)}=\left[\frac{3}{u^{3}}(\sin (u)-u \cos (u))\right]^{2}
$$

For a sphere, $\mathrm{u}$ is defined as:

$$
u=q * r_{p}
$$

with $r_{p}$ the sphere's radius and $q$ the wave vector, defined as: 


$$
q=\frac{4 \pi}{\lambda} \sin \left(\frac{\theta}{2}\right)
$$

with $\lambda$ the wavelength of scattered light, which is $658 \mathrm{~nm}$. So we have:

$$
u=\frac{2 \pi D_{z H} \sin \left(\frac{\theta}{2}\right)}{\lambda}
$$

For a sphere the $\mathrm{M}_{\mathrm{w}}$ is proportional to the sphere volume:

$$
M_{W} \propto\left(\frac{D_{z H}}{2}\right)^{3}
$$

So, equation $\mathrm{S} 7$ can be written as:

$$
I_{(\theta, c)} \propto K c\left(\frac{D_{z H}}{2}\right)^{3}\left[\frac{3}{u^{3}}(\sin (u)-u \cos (u))\right]^{2}
$$

Since, $\mathrm{c}$ is proportional to the particle concentration $\mathrm{n}$ and $\mathrm{K}$ and $\mathrm{\Theta}$ are held constant, so:

$$
n \propto \frac{I_{(\theta, c)}}{\left(\frac{D_{z H}}{2}\right)^{3}\left[\frac{3}{u^{3}}(\sin (u)-u \cos (u))\right]^{2}}
$$

Equation S14 can be simplified to:

$$
n \propto \frac{I_{(\theta, c)}}{\left(\frac{9}{q^{6} r_{p}^{3}}\right)(\sin (u)-u \cos (u))^{2}}
$$



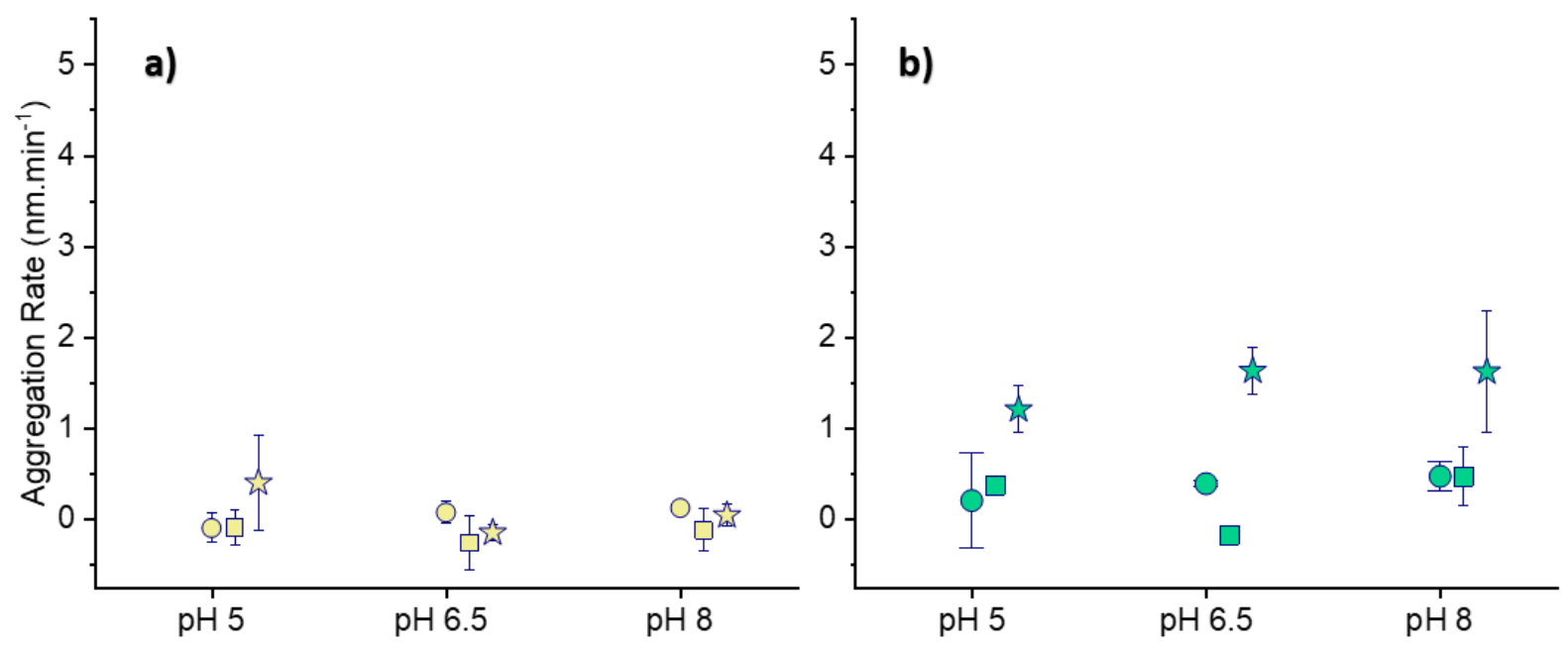

Figure S9: Aggregation rate of NPT-P with a) $30 \mathrm{mg} \mathrm{L}^{-1}$ humic acid b) $57 \mathrm{mg} \mathrm{L}^{-1}$ sodium alginate, as a function of ionic strength and $\mathrm{pH}$ (Error bars $=$ standard deviation $)$

\section{References :}

Elimelech, M. (Ed.), 1998. Particle deposition and aggregation: measurement, modelling and simulation, Colloid and surface engineering series. Butterworth-Heinemann, Oxford.

Gigault, J., El Hadri, H., Reynaud, S., Deniau, E., Grassl, B., 2017. Asymmetrical flow field flow fractionation methods to characterize submicron particles: application to carbon-based aggregates and nanoplastics. Analytical and Bioanalytical Chemistry 409, 6761-6769. https://doi.org/10.1007/s00216-017-0629-7

Gregory, J., 1981. Approximate expressions for retarded van der waals interaction. Journal of Colloid and Interface Science 83, 138-145. https://doi.org/10.1016/0021-9797(81)90018-7

Hogg, R., Healy, T.W., Fuerstenau, D.W., 1966. Mutual coagulation of colloidal dispersions. Trans. Faraday Soc. 62, 1638. https://doi.org/10.1039/tf9666201638

Masuelli, M.A., Illanes, C.O., 2014. Review of the characterization of sodium alginate by intrinsic viscosity measurements. Comparative analysis between conventional and single point methods. International Journal of BioMaterials Science and Engineering 1, 11.

Valsesia, A., Desmet, C., Ojea-Jiménez, I., Oddo, A., Capomaccio, R., Rossi, F., Colpo, P., 2018. Direct quantification of nanoparticle surface hydrophobicity. Commun Chem 1, 53. https://doi.org/10.1038/s42004-018-0054-7

van Oss, C.J., 1993. Acid — base interfacial interactions in aqueous media. Colloids and Surfaces A: Physicochemical and Engineering Aspects 78, 1-49. https://doi.org/10.1016/0927-7757(93)80308-2

Verleysen, E., Wagner, T., Lipinski, H.-G., Kägi, R., Koeber, R., Boix-Sanfeliu, A., De Temmerman, P.-J., Mast, J., 2019. Evaluation of a TEM based Approach for Size Measurement of Particulate (Nano)materials. Materials 12, 2274. https://doi.org/10.3390/ma12142274

Wyatt, P.J., 1993. Light scattering and the absolute characterization of macromolecules. Analytica Chimica Acta 272, 1-40. https://doi.org/10.1016/0003-2670(93)80373-S 